\title{
ARTICLE \\ Exploring the protective effects of schizandrol A in acute myocardial ischemia mice by comprehensive metabolomics profiling integrated with molecular mechanism studies
}

\author{
Qiong Lai ${ }^{1}$, Guang-ying Yuan ${ }^{1}$, Hao Wang ${ }^{2}$, Ze-liang Liu ${ }^{1}$, Jun-ping Kou ${ }^{1}$, Bo-yang Yu ${ }^{1}$ and Fang $\mathrm{Li}^{1}$
}

\begin{abstract}
Schizandrol A (SA) is an bioactive component isolated from the Schisandra chinensis (Turcz.) Baill., which has been used as a remedy to prevent oxidative injury. However, whether the cardioprotective effect of SA is associated with regulating endogenous metabolites remains unclear, thus we performed comprehensive metabolomics profiling in acute myocardial ischemia (AMI) mice following SA treatment. AMI was induced in ICR mice by coronary artery ligation, then SA $\left(6 \mathrm{mg} \cdot \mathrm{kg}^{-1} \cdot \mathrm{d}^{-1}\right.$, ip) was administered. SA treatment significantly decreased the infarct size, preserved the cardiac function, and improved the biochemical indicators and cardiac pathological alterations. Moreover, SA (10, $100 \mathrm{M})$ significantly decreased the apoptotic index in OGD-treated H8c2 cardiomycytes in vitro. By using HPLC-Q-TOF/MS, we conducted metabonomics analysis to screen the significantly changed endogenous metabolites and construct the network in both serum and urine. The results revealed that SA regulated the pathways of glycine, serine and threonine metabolism, lysine biosynthesis, pyrimidine metabolism, arginine and proline metabolism, cysteine and methionine metabolism, valine, leucine and isoleucine biosynthesis under the pathological conditions of AMI. Furthermore, we selected the regulatory enzymes related to heart disease, including ecto-5'-nucleotidase (NT5E), guanidinoacetate Nmethyltransferase (GAMT), platelet-derived endothelial cell growth factor (PD-ECGF) and methionine synthase (MTR), for validation. In addition, SA was found to facilitate PI3K/Akt activation and inhibit the expression of NOX2 in AMI mice and OGD-treated H9c2 cells. In conclusion, we have elucidated SA-regulated endogenous metabolic pathways and constructed a regulatory metabolic network map. Furthermore, we have validated the new potential therapeutic targets and underlying molecular mechanisms of SA against AMI, which might provide a reference for its future application in cardiovascular diseases.
\end{abstract}

Keywords: schizandrol A; cardioprotective effect; acute myocardial ischemia mice; OGD-treated H9c2 cardiomycytes; metabonomics; metabolic pathways; therapeutic targets

Acta Pharmacologica Sinica (2020) 41:1058-1072; https://doi.org/10.1038/s41401-020-0377-7

\section{INTRODUCTION}

Cardiovascular disease (CVD) remains the leading cause of mortality and morbidity worldwide, and approximately $50 \%$ of CVD cases are associated with ischemic heart disease [1]. Acute myocardial ischemia (AMI) is a severe cardiovascular disease that is due to a sudden decrease in blood flow and oxygen supply to the heart, consequently leading to cardiac dysfunction, cardiac metabolic disorder, myocardial infarction, and even death [2]. It is widely acknowledged that the molecular mechanisms of AMI are complex and involve multiple pathways. This complexity offers the opportunity for metabolomics studies to uncover new insights into the progression of AMI. Currently, $\beta$-blockers, statins and angiotensin-converting enzyme inhibitors are the mainstays of current treatment [3]. However, these treatments provide limited symptomatic relief, and the attempts to treat AMI thus far have been far from sufficient.
Schizandrol A (SA) is a bioactive component isolated from Schisandra chinensis (Turcz.) Baill. and is also one of the major effective ingredients of the well-known TCM formula ShengMai preparations, which acts as a remedy to prevent oxidative injury and treat coronary heart diseases $[4,5]$. Previous studies have reported that SA exerts protective effects against H/R-induced vascular endothelial injury and glutamate-induced neuronal excitotoxicity [6-8] and that SA also exhibits anti-inflammatory activity [9]. In our previous study, a new drug combination comprising ginsenoside $\mathrm{Rb} 1$, ruscogenin and SA (GRS; 6:0.75:6 ratio) was shown to be effective in mitigating myocardial ischemia/reperfusion injury by suppressing mitochondrial-mediated apoptosis [10]. As a component of this drug combination, SA showed cardioprotective effects against acute myocardial infarction [11]. However, the molecular mechanism of the functions of SA against AMI remains unclear, and further studies are still needed to elucidate this mechanism.

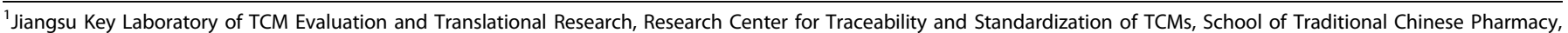

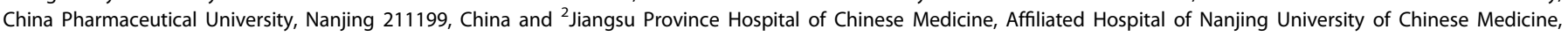
Nanjing University of Chinese Medicine, Nanjing 210046, China

Correspondence: Bo-yang Yu (boyangyu59@163.com) or Fang Li (lifangcpu@163.com)

These authors contributed equally: Qiong Lai, Guang-ying Yuan
}

Received: 14 October 2019 Accepted: 11 February 2020

Published online: 2 March 2020 
Currently, metabolomics, which provides comprehensive profiling of small molecular substances in biological systems, is being increasingly applied to elucidate disease mechanisms and understand potential new drug targets [12]. Recently, there has been an increasing number of metabolomics investigations of cardiovascular diseases. Recent studies have identified 12 panels of specific biomarkers useful for the diagnosis of coronary artery disease based on metabolomics analysis of plasma samples from 2324 patients from 4 independent centers [13]. Moreover, in a further study, a functional metabolomics strategy was employed to characterize metabolite signatures associated with coronary artery disease. Neu5Ac was identified as a key metabolite, and its regulatory enzyme neuraminidase- 1 may serve as a new avenue for therapeutic intervention for myocardial ischemia injury [14]. Li et al. conducted comprehensive profiling of the rat plasma and heart in response to AMI and Danqi Tongmai tablets via LC-MSbased metabolomics and lipidomics [15]. However, there have been few studies on the cardioprotective effects of SA from the perspective of metabonomics. Therefore, in our present study, metabonomics technology was employed to clarify the specific metabolic pathways modulated by SA to induce improvements in AMI. Furthermore, endogenous metabolites differentially regulated by SA were identified, and a regulatory metabolic network map was constructed. Several novel potential therapeutic targets closely related to cardiovascular diseases were selected, and the effects of SA on these targets were verified. We hope this work will help us understand more about the mechanisms of SA from the perspective of endogenous metabolites and provide some references for the investigation of SA in the future.

\section{MATERIALS AND METHODS}

Reagents and materials

Acetonitrile, methanol and formic acid were obtained from Merck (Darmstadt, Germany). Ultrapure water was obtained from a MilliQ purification system (Milford, MA, USA). Schizandrol A (SA) was purchased from Chengdu Pufei De Biotech Co., Ltd. (Chengdu, China; purity: HPLC $\geq 98 \%$, lot number: 16103103). Metoprolol tartrate tablets were obtained from AstraZeneca (Taizhou, China; lot number: 1611A74). Creatine kinase (CK) and lactate dehydrogenase (LDH) assay kits were purchased from Nanjing Jiancheng Bioengineering Institute (Nanjing, China). C-reactive protein (CRP), tumor necrosis factor-a (TNF-a), and cardiac troponin I (cTn-I) assay kits were obtained from Nanjing Jin Yibai Biological Technology Co., Ltd (Nanjing Jin, China). Antibodies against GAPDH were purchased from Shanghai KangChen Biotech Inc. (Shanghai, China). Antibodies against PD-ECGF, MTR, and NT5E were obtained from Proteintech (Wuhan, China). Antibodies against $\beta$-actin and GAMT were purchased from Bioworld Technology (St. Louis Park, MN, USA). Antibodies against PI3K, Akt, p-Akt, and NOX2 were purchased from Cell Signaling Technology (Boston, MA, USA).

Animals and the AMI injury model

ICR male mice (8 weeks old, 22-25 g) were purchased from the Experimental Animal Center of Yangzhou University (Yangzhou, China; certificate No SCXK 2017-0007). All animals were housed individually in cages under hygienic conditions and placed in an environment with controlled temperature $\left(23 \pm 1{ }^{\circ} \mathrm{C}\right)$, humidity $(30 \%-40 \%)$ and light (12-h light/dark cycle) with commercial standard solid rodent chow and water provided ad libitum. All animal welfare and experimental procedures were in accordance with the National Institutes of Health Guide for the Care and Use of Laboratory Animals, and the protocols used were approved by the Animal Ethics Committee of China Pharmaceutical University, China Pharmaceutical University, Nanjing, China.

The AMI model was produced as previously described [16], and the rats were anesthetized with sodium pentobarbital $(50 \mathrm{mg} / \mathrm{kg})$ intraperitoneally (i.p.). The adequacy of anesthesia was controlled by monitoring the lack of response to toe pinch. Then, the chest wall was shaved, and left thoracotomy was performed. A 6-0 silk suture was tied around the left anterior descending coronary artery approximately 3-4 mm from its origin. Sham-operated mice were subjected to the same surgical procedures without ligation of the left anterior descending coronary artery. Successful myocardial ischemia injury by complete ligation of the left ascending (LAD) coronary artery was confirmed by the occurrence of ST-segment elevation on an electrocardiogram monitor.

The mice were randomly divided into four groups ( $n=8 /$ group): (1) the sham group (normal saline, i.p.); (2) the model group (normal saline, i.p.); (3) the SA group (SA, i.p.); (4) and the metoprolol (positive control drug) group (Met, i.g.). The dosage of SA in this experiment was $6 \mathrm{mg} \cdot \mathrm{kg}^{-1}$. day ${ }^{-1}$, which was based on the effective dose identified in our previous study [11]. The clinically used dosage of Met was converted for use in our experiment, and the dosage was determined to be $5.14 \mathrm{mg} \cdot \mathrm{kg}^{-1} \cdot \mathrm{day}^{-1}$. All drugs were administered intraperitoneally after $20 \mathrm{~min}$ of ischemia.

\section{TTC staining}

After $24 \mathrm{~h}$ of ligation, the mice were euthanized and perfused with PBS by LV puncture. One-millimeter short-axis sections of the heart were incubated in $1 \% \pi C$ solution at $37^{\circ} \mathrm{C}$ for $15 \mathrm{~min}$. The infarcted area was analyzed using ImageJ software (Bethesda Md, USA).

Blood sample analysis

At the end of the experiment, blood samples were obtained. Serum samples were collected by centrifuging the blood samples at $3500 \mathrm{rpm}$ for $10 \mathrm{~min}$. Then, the supernatant was obtained and immediately stored at $-70^{\circ} \mathrm{C}$ until analysis. The activities of $\mathrm{CK}$ and LDH and the content of CRP, TNF-a, and cTn-I in the serum were determined with commercial kits according to the manufacturer's instructions.

\section{Echocardiography}

After $24 \mathrm{~h}$ of ligation, cardiac function was evaluated using an echocardiographic system consisting of a Vevo 2100 Imaging System (Visual Sonics, Toronto, Canada) equipped with a $30 \mathrm{MHz}$ transducer. The mice were anesthetized with isoflurane in $\mathrm{O}_{2}$ gas. After anesthetization, each mouse was placed on a heated imaging platform. The following parameters were calculated: left ventricular (LV) ejection fraction (EF) ((LVEDV-LVESV)/LVEDV), LV fractional shortening (FS) ((LVDd-LVDs)/LVDd), and stroke volume (SV) (LV Vold-LV Vols).

Hematoxylin-eosin staining of the heart Heart samples from each group were fixed in 10\% phosphatebuffered formalin for $24 \mathrm{~h}$. Next, the samples were embedded in paraffin wax, and $4-\mu \mathrm{m}$ to $5-\mu \mathrm{m}$ histological sections of the paraffin-embedded tissues were stained with hematoxylin-eosin. The sections were imaged under a light microscope (DX45, Olympus Microsystems Ltd., Japan) [17].

Masson's trichrome staining

Paraffin-embedded heart sections $(4-\mu m$ to $5-\mu m$ thick) were stained with Masson's trichrome. Normal tissue appeared red, and collagen tissue appeared blue. The heart sections were imaged at high pixel resolution with an OLYMPUS DP72 digital camera.

\section{Cell preparation and culture}

The rat cardiomyocyte cell line $\mathrm{H} 9 \mathrm{c} 2$ was purchased from Shanghai Institute of Cell Biology, Chinese Academy of Sciences (Shanghai, China). The H9c2 cells were maintained in DMEM supplemented with $10 \% \mathrm{FBS}$ at $37^{\circ} \mathrm{C}$ in a humidified atmosphere of $5 \% \mathrm{CO}_{2}$. The cells were subcultured or subjected to experimental procedures at $80 \%-90 \%$ confluence. 
Oxygen glucose deprivation (OGD)-treated cell model and drug treatment

To mimic ischemic injury in vitro, the OGD model was employed. OGD injury was induced by incubating cells with glucose-free DMEM and exposing them to a hypoxic environment of $94 \% \mathrm{~N}_{2}$, $5 \% \mathrm{CO}_{2}$, and $1 \% \mathrm{O}_{2}$ for $6 \mathrm{~h}$. The cells were treated with SA (1-100 $\mu \mathrm{M})$ during hypoxia.

\section{Cell viability and LDH assays}

Cell viability was detected using the MTT assay. After different treatments, cells were incubated with MTT at a final concentration of $0.5 \mathrm{mg} / \mathrm{mL}$ for $3 \mathrm{~h}$. Then, the medium was discarded, and $150 \mu \mathrm{L}$ of DMSO was added to dissolve the formazan crystals. The absorbance was read at $570 \mathrm{~nm}$ with a reference wavelength of $650 \mathrm{~nm}$, and cell viability was calculated as the percentage of absorbance relative to the control value. In addition, the release of $\mathrm{LDH}$ was also determined to measure the extent of cell injury. At the end of the incubation, the culture supernatant was collected, and LDH was detected at $490 \mathrm{~nm}$.

\section{TUNEL staining}

Apoptotic cells were detected using the TUNEL Apoptosis Assay Kit according to the manufacturer's instructions as previously described [6]. Five fields from each slice were randomly analyzed under a confocal scanning microscope (LSM700, Zeiss, USA). The extent of cell apoptosis was expressed as the ratio of TUNELpositive nuclei.

\section{Flow cytometry analysis}

FITC-conjugated Annexin V and PI were used to detect apoptotic cells. H9c2 cardiomyocytes were harvested, washed with PBS, and resuspended in binding buffer, and then FITC-Annexin-V and PI were added at a final concentration of $100 \mathrm{ng} / \mathrm{mL}$. The mixture was incubated for $15 \mathrm{~min}$ in the dark and analyzed with a flow cytometer.

\section{Untargeted metabonomics analysis}

Sample pretreatment. Serum and urine were collected after ligation for $24 \mathrm{~h}$. Serum samples were obtained by centrifuging the blood samples at $3500 \mathrm{rpm}$ for $10 \mathrm{~min}$ at $15^{\circ} \mathrm{C}$. Urine samples were collected at $4{ }^{\circ} \mathrm{C}$. All samples were kept at $-80^{\circ} \mathrm{C}$ until analysis. For untargeted extraction, $200 \mu \mathrm{L}$ aliquots of serum and urine were precipitated by adding $600 \mu \mathrm{L}$ of methanol and mixed for $60 \mathrm{~s}$. The precipitated proteins were subsequently removed by centrifugation $(13,000 \mathrm{rpm}, 20 \mathrm{~min})$ at $4{ }^{\circ} \mathrm{C}$. Then, $150 \mu \mathrm{L}$ of the supernatants were collected and dried under a gentle stream of nitrogen at room temperature. Finally, the supernatants were reconstituted with $100 \mu \mathrm{L}$ of methanol for further analysis.

HPLC-Q-TOF MS analysis. Metabolite separation was performed using an Agilent Technologies 6530 Accurate-Mass Q-TOF LC/MS system (USA). The mobile phase consisted of water with $0.1 \%$ formic acid (eluent A) and acetonitrile with $0.1 \%$ formic acid (eluent B). Serum analyses were archived on a Synergi ${ }^{\mathrm{TM}}$ Fusion-RP C18 column $(50 \mathrm{~mm} \times 2 \mathrm{~mm}$ i.d., $2.5 \mu \mathrm{m})$. The gradient program began with $5 \% \mathrm{~B}$ at $0-2 \mathrm{~min}, 5 \%-60 \% \mathrm{~B}$ at $2-10 \mathrm{~min}, 60 \%-70 \% \mathrm{~B}$ at $10-15 \mathrm{~min}, 70 \%-80 \% \mathrm{~B}$ at $15-20 \mathrm{~min}, 80 \%-95 \% \mathrm{~B}$ at $20-22 \mathrm{~min}$, $95 \%-60 \%$ B at $22-28 \mathrm{~min}$, and $60 \%-30 \% \mathrm{~B}$ at $28-30 \mathrm{~min}$ and then returned to the initial conditions with 2 min for equilibration. The flow rate was $0.4 \mathrm{~mL} / \mathrm{min}$. Urine analyses were performed on a TSK-GEL Amide- 80 column $(150 \mathrm{~mm} \times 2.0 \mathrm{~mm}$ i.d., $5 \mu \mathrm{m})$. The gradient program began with $90 \% \mathrm{~B}$ at $0-5 \mathrm{~min}, 90 \%-50 \% \mathrm{~B}$ at 5-10 min, $50 \%-50 \%$ B at $10-14 \mathrm{~min}$, and $50 \%-90 \%$ B at $14-16 \mathrm{~min}$ and then returned to the initial conditions with 2 min for equilibration. The flow rate was $0.2 \mathrm{~mL} / \mathrm{min}$. The sample injection volumes were $5 \mu \mathrm{L}$. Mass spectrometry was performed with an electrospray ionization ion source in the positive $\left(\mathrm{ESI}^{+}\right)$and negative $\left(\mathrm{ESI}^{-}\right)$ion modes. The MS parameters were set as follows: a fragmental voltage of $120 \mathrm{~V}$, a nebulizer gas of $35 \mathrm{psig}$, a capillary voltage of $4000 \mathrm{~V}$, a drying gas flow rate of $9 \mathrm{~L} / \mathrm{min}$, and a temperature of $325^{\circ} \mathrm{C}$. The data were collected in centroid and profile modes with a mass range of $50-1500 \mathrm{~m} / \mathrm{z}$ using the highresolution mode $(4 \mathrm{GHz})$.

Method validation. The repeatability and robustness of the analytical procedure were validated by using the pooled quality control (QC) sample. The QC sample was prepared by mixing 200 $\mu \mathrm{L}$ of each test sample, and the pretreatment method of the QC samples was the same as that of the test samples. The QC sample was divided into five aliquots, which were randomly injected throughout the sequence list. Unsupervised PCA analysis showed good repeatability and robustness of the analytical method, as indicated by the tight grouping of the QC samples in the score plot (Supplementary Fig. S3). Meanwhile, we overlapped the total ion chromatograms (TICS) of the QC samples, as shown in Supplementary Fig. S4, which showed that the response intensity and retention time of each chromatographic peak basically overlapped. These data all demonstrated the high reproducibility of the method and the stability of the instrument during the experiment.

Data processing. The raw data (.d) acquired from Q-TOF LC/MS $\mathrm{ESI}^{+}$and $\mathrm{ESI}^{-}$analysis were transformed to data format (.mzdata) files by MassHunter Workstation Software (Version B.06.00, Agilent Technologies). Using R Foundation for Statistical Computing, data pretreatment procedures such as nonlinear retention time alignment, peak discrimination, filtering, alignment, and matching were performed with the XCMS package (http://metlin.scripps. edu/download/). Ion features that were present in less than $80 \%$ of the samples were screened out. The intensities of each peak detected were generated by virtue of the retention times and the $\mathrm{m} / \mathrm{z}$ data pairs for each ion. After being normalized to total peak intensity, log-transformed and Pareto scaled, the processed data were imported into SIMCA-P 14.1 (Umetrics, Sweden) and MetaboAnalyst (https://www.metaboanalyst.ca/), where they were subjected to multivariate data analyses, including Pareto-scaled principal component analysis (PCA) and orthogonal partial leastsquares discriminant analysis (OPLS-DA). Metabolites with a VIP value $>1$ were further subjected to Student's $t$-test at the univariate level to measure the significance of each metabolite, and $P$-values less than 0.05 were considered statistically significant.

Western blot analysis. As reported [6], cells were lysed in icecold RIPA buffer supplemented with $1 \mathrm{mM}$ PMSF. The infarct areas of heart tissues were homogenized in RIPA buffer. The protein concentrations were quantified with a BCA assay kit following the manufacturer's instructions. Equal amounts of proteins $(40 \mu \mathrm{g})$ were electrophoresed on SDS-PAGE gels, transferred to PVDF membranes, and blocked with 5\% BSA solution. The blots were probed with primary antibodies overnight at $4{ }^{\circ} \mathrm{C}$ and then incubated with the appropriate secondary antibodies at room temperature for $2 \mathrm{~h}$. The ECL plus system was used to detect the protein signal. The band densities were visualized by the ChemiDoc ${ }^{\mathrm{TM}}$ MP System (Bio-Rad), and the relative values were expressed relative to the signal of GAPDH or $\beta$-actin.

Immunohistochemistry. Twenty-four hours after ligation, the hearts were collected and processed for immunohistochemistry to analyze the expression of ecto-5'-nucleotidase (NT5E) and methionine synthase (MTR). The heart tissues were fixed in $4 \%$ paraformaldehyde and embedded in paraffin. The heart tissues were sectioned at a thickness of $4 \mu \mathrm{m}$, deparaffinized, rehydrated in PBS, and incubated with 3\% hydrogen peroxide to block endogenous peroxidase activity. Then, the sections were 
incubated for $1 \mathrm{~h}$ at $37^{\circ} \mathrm{C}$ with blocking liquid (Beyotime, Shanghai, China). Primary antibodies against MTR and NT5E (1:100) were added dropwise to the sections, and the sections were incubated at $4{ }^{\circ} \mathrm{C}$ for $24 \mathrm{~h}$. After washing, the sections were incubated with the HRP-conjugated secondary antibody (1:200, Biogot Technology, Nanjing, China) at $37^{\circ} \mathrm{C}$ for $1 \mathrm{~h}$. After incubation with $\mathrm{DAB}$ and counterstaining with hematoxylin, a light microscope (DX45, Olympus Microsystems Ltd., Japan) was used to observe the dehydrated sections, and the sections were imaged at $\times 400$ magnification.

Immunofluorescence staining. Slices of heart tissues were washed with ice-cold PBS, fixed in 4\% paraformaldehyde, permeabilized with $0.1 \%$ Triton X-100 in PBS for 30 min, blocked with 5\% BSA, and incubated with a rabbit PD-ECGF antibody at a 1:200 dilution overnight at $4{ }^{\circ} \mathrm{C}$ followed by an Alexa Fluor 488-conjugated donkey anti-rabbit antibody at a 1:200 dilution for $2 \mathrm{~h}$. Nuclei were visualized using DAPI. Fluorescence was observed with a confocal laser scanning microscope.

Statistical analysis. All values in the text and figures are expressed as the mean \pm SEM. Statistical analysis was carried out using Student's two-tailed $t$-test for comparisons between two groups and one-way analysis of variance (ANOVA) followed by Dunnett's test for comparisons between three or more groups. $P<0.05$ was considered significant.

\section{RESULTS}

SA ameliorated myocardial injury and improved cardiac function in AMI mice

Mice were treated with SA by intraperitoneal administration after $2 \mathrm{~h}$ of myocardial ischemia induced by coronary artery ligation. The myocardial infarct size and some serum biochemical indicators were measured to evaluate the effect of SA on AMI. As illustrated in Fig. 1, 24h of ischemia resulted in myocardial injury, as evidenced by an increased infarct size, increased CK and LDH activities, and increased levels of CTn-I, CRP, and TNF-a. However, SA and Met treatment significantly inhibited the increase in infarct size (Fig. 1a, b). Simultaneously, $S A$ and Met markedly reduced the activities of $C K$ and LDH (Fig. 1c, d), as well as the levels of CTn-I, CRP, and TNF-a (Fig. 1e-g).

Furthermore, echocardiography was performed to detect the effects of SA on cardiac performance. As shown in Fig. 2, compared to sham surgery, AMI significantly impaired the LVEF, LVFS, and SV. In contrast, SA and Met markedly attenuated the AMl-induced impairment of cardiac function (Fig. 2a-d). In addition, histopathological examination of AMI mouse heart tissues revealed widespread myocardial structural disarray, a large number of inflammatory cells infiltrating the myocardial tissue and increased left ventricular wall fibrosis. The histological features were normalized or became milder, showing marked improvement, after SA treatment (Fig. 2e-h). a

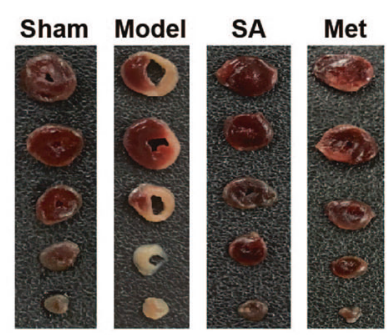

b

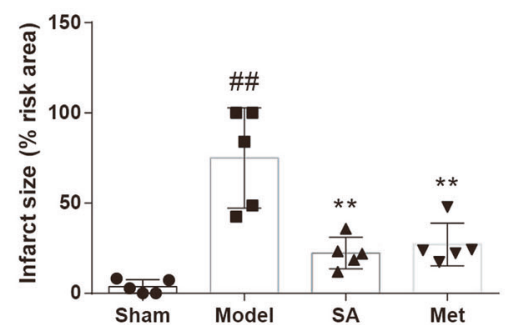

C

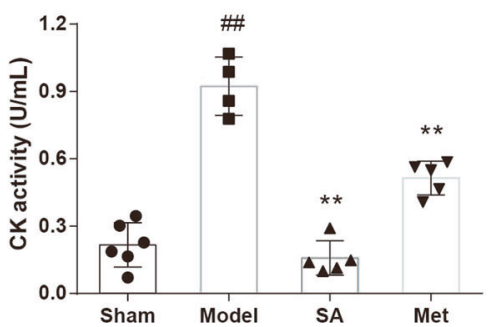

d

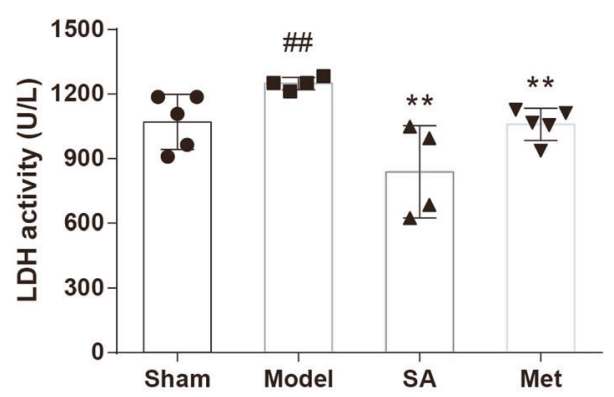

f



e

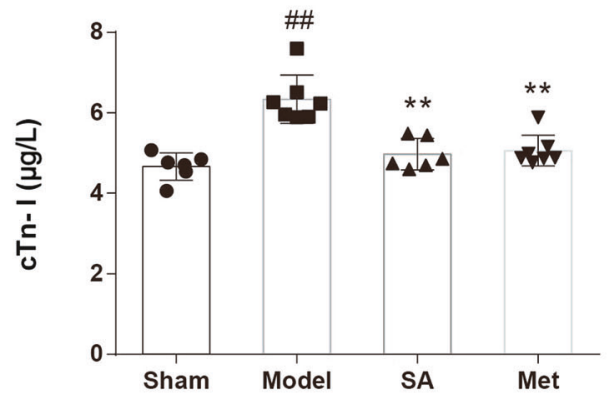

g



Fig. 1 Effect of SA on AMI-induced myocardial injury. a TTC staining of the myocardial infarct area. $\mathbf{b}$ Graphic representation of the myocardial infarct size. c CK activity. d LDH activity. e cTn-I content. f CRP content. g TNF- $\alpha$ content. ${ }^{\# \# ~} P<0.01$ vs. the sham group, ${ }^{* * *} P<0.01$ vs. the model group 
a

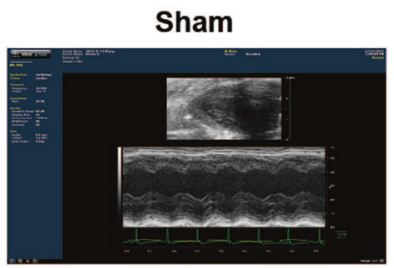

b

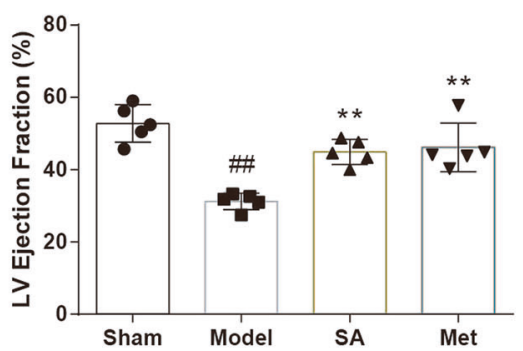

Model

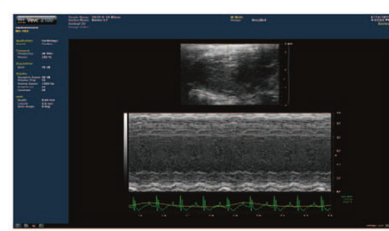

C

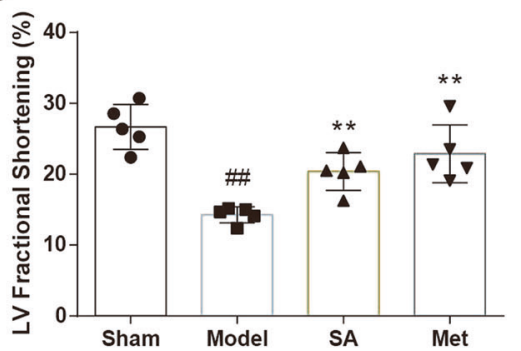

SA

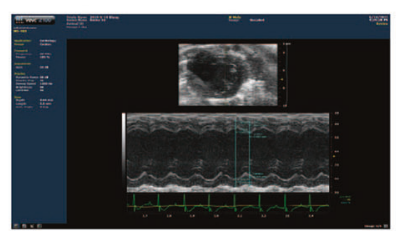

Met

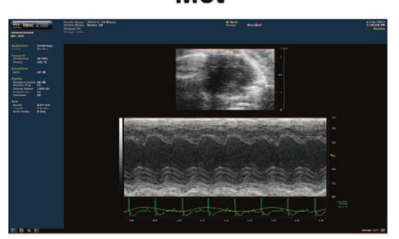

d

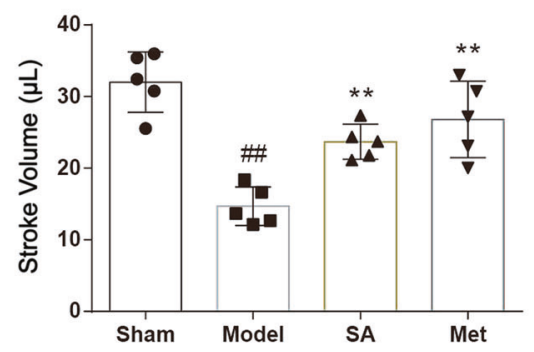

e

Sham

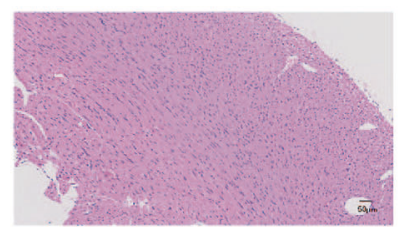

f



9

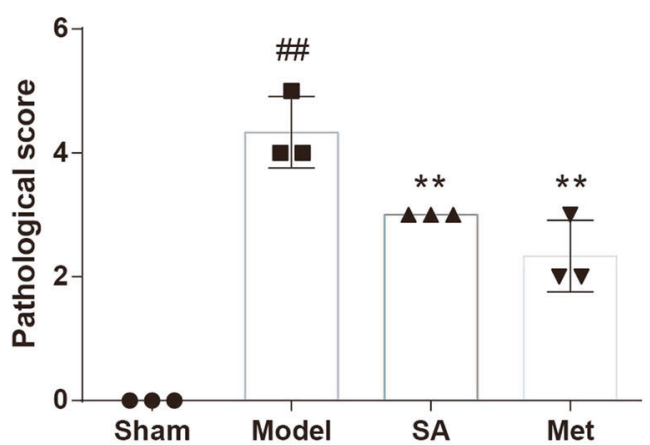

Model

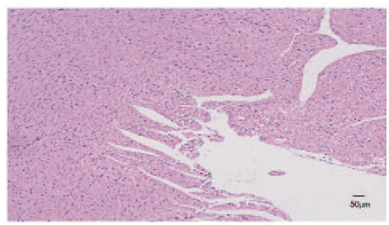

Model

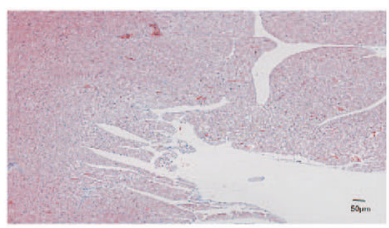

h
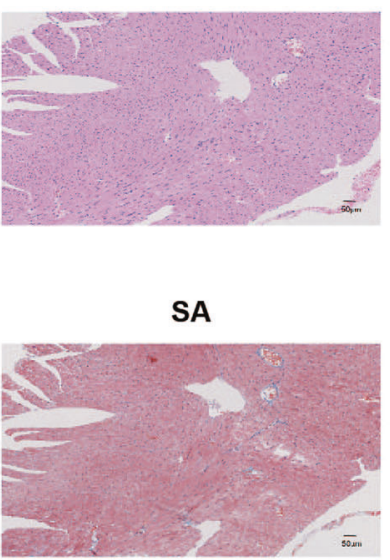

Met



Met
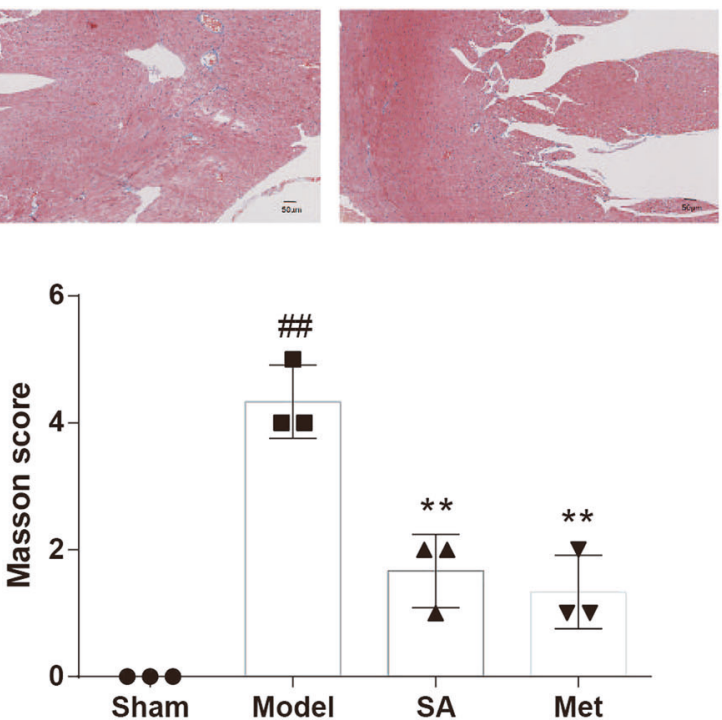

Fig. 2 Effect of SA on AMI-induced cardiac function and pathological changes. a Representative echocardiography images. The LVEF (b), LVFS (c), and SV (d) were measured by echocardiography. e Representative H\&E staining results. f Representative Masson's trichrome staining results. g Histopathological change scores. h Fibrosis scores. ${ }^{\# \#} P<0.01$ vs. the control group, ${ }^{* *} P<0.01$ vs. the model group

SA inhibited myocardial apoptosis in AMI mice and OGD-induced cardiomyocyte apoptosis

As shown in Fig. 3, the exposure of H9c2 cardiomyocytes to OGD led to a decrease in cell viability, whereas treatment with SA maintained cell viability (Fig. $3 a$ ). As $\mathrm{LDH}$ release is a recognized marker of cell injury, the release of LDH into the culture medium was also investigated. Compared to that in the control group, $\mathrm{LDH}$ release significantly increased after OGD injury, while treatment with SA markedly inhibited the release of LDH (Fig. 3b).

Myocardial apoptosis is an essential element associated with infarct size expansion and cardiac dysfunction after ischemic injury [18]. Therefore, flow cytometry analysis and TUNEL staining were employed to explore whether SA prevented AMI-induced myocardial apoptosis. Quantitative analysis using flow cytometry confirmed that the apoptotic index was markedly increased compared with that of 
a

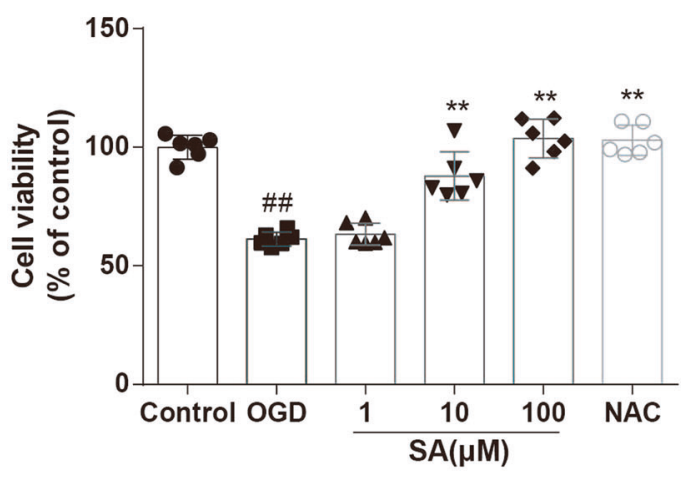

C

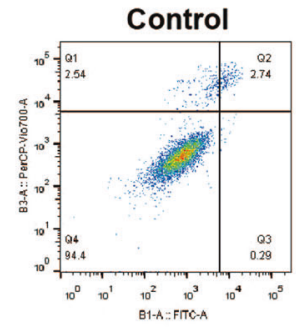

SA

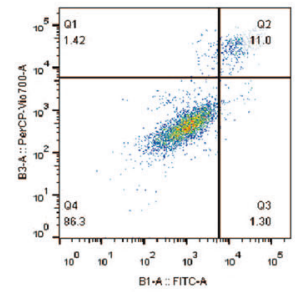

e
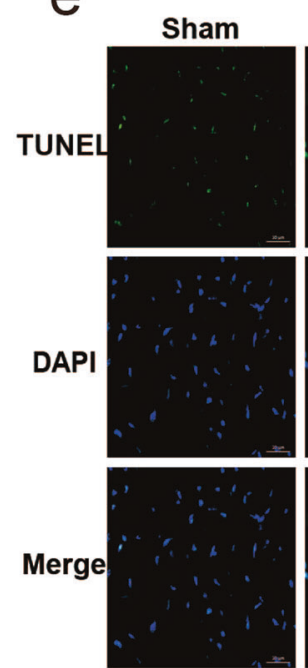

Model
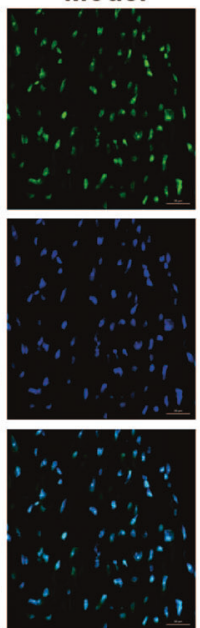

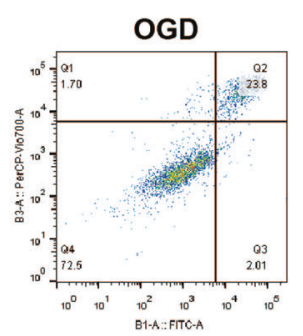

NAC



SA
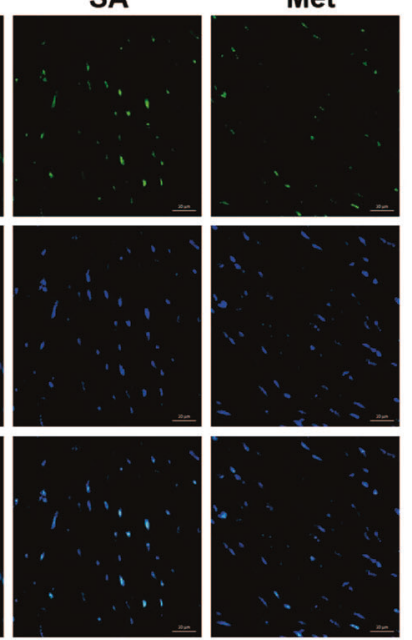

b



d

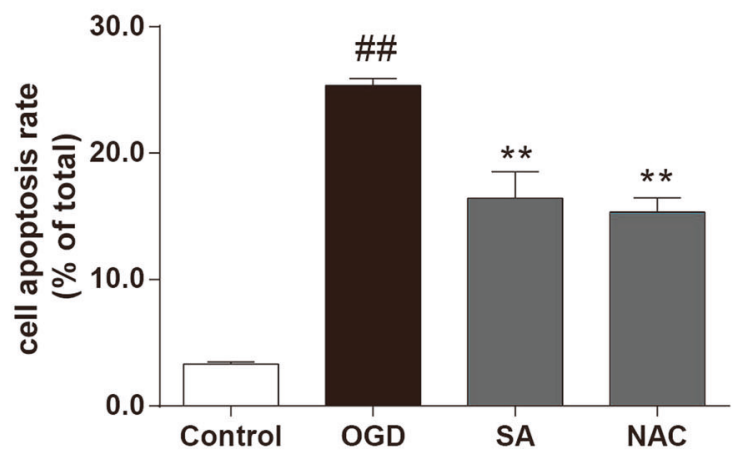

f

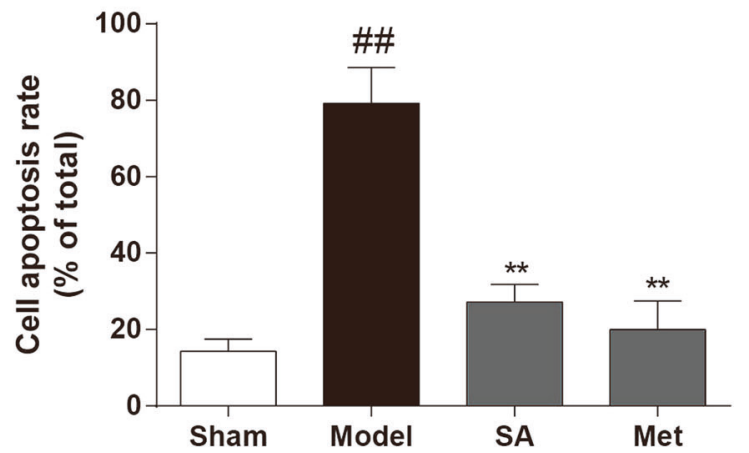

Fig. 3 Effect of SA on AMI-induced myocardial apoptosis and OGD-induced cardiomyocyte apoptosis. a H9c2 cardiomyocytes were treated with SA followed by OGD, and cell viability was determined by the MTT assay. $\mathbf{b}$ The release of LDH in the culture medium of H9c2 cardiomyocytes was determined at the end of OGD. c The OGD-induced cell apoptosis rate was quantified by flow cytometry. d Quantitative analysis of apoptotic cells in the indicated groups. e Representative photomicrographs of TUNEL staining in AMI mice. $\mathbf{f}$ Quantitative analysis of apoptotic cells in AMI mice. ${ }^{\# \#} P<0.01$ vs. the control group, ${ }^{* *} P<0.01$ vs. the model group

the control group. However, the apoptotic index was significantly decreased by treatment with SA (Fig. 3c, d). Compared to the shamtreated mice, the AMI mice exhibited obvious TUNEL-positive (apoptosis) cells in the ischemic myocardium following AMI. In contrast, a markedly lower proportion of apoptotic cells was observed in heart slices from SA-treated mice (Fig. 3e, f).
Principal component and orthogonal partial least squares discriminant analyses of serum and urine samples

Principal component analysis (PCA) was used to perform unsupervised data analysis on the sham, model and SA groups. Most of these groups could be easily distinguished from each other. Supplementary Fig. S4 shows that the farthest distance was 
observed between the model group and sham operation group. However, the SA-treated samples were closer to the sham operation group than the model group. These results further indicated that SA improved myocardial ischemia, as myocardial ischemia mice were increasingly similar to healthy mice after SA administration.

We further used OPLS-DA for supervised data analysis to elucidate the metabolic variations. All data acquired from the urine and serum were analyzed using SIMCA-P software for the discrimination and selection of significant variables. The OPLS-DA model was constructed to determine the distinction of metabolic patterns between the model group and SA group in both the positive and negative ion modes. In theory, the R2Y and Q2 values should be close to 1 , which indicates a high predictive ability [19]. As shown in Table 1, the parameters of model quality reflected the good fitness and predictability of OPLS-DA. Moreover, as illustrated in Fig. 4a-d, the metabolic profiles of both urine and serum samples from the model group were distinctly different from those of urine and serum samples from the SA group. Next, an S-plot was employed to identify altered metabolites that markedly contributed to the differences between the model and SA groups (Fig. 4e-h). The metabolites with VIP values over 1 and $P$-values lower than 0.05, which are listed in Tables 2, 3, were considered potential biomarkers [20].

In addition, a hierarchical clustering heatmap was applied to view the data more intuitively. The heatmap indicated that the concentrations of metabolic biomarkers in the SA group differed from those in the model group (Fig. 5).

Enrichment analysis of metabolic pathways and regulatory enzymes

To reveal the metabolic processes of the metabolites, the metabolites that were significantly changed in the serum and urine were entered into MetaboAnalyst 4.0 (https://www. metaboanalyst.ca/) for pathway enrichment analysis. Twenty associated pathways in total were identified. According to the enrichment fold of the pathways, the major modulated pathways involved were glycine, serine and threonine metabolism, glycerolipid metabolism, pyrimidine metabolism, spermidine and spermine biosynthesis, and methionine metabolism (Fig. 6a-c). Furthermore, pathway and enrichment analysis of related regulatory enzymes was performed by STRING (https://string-db. org/) and Metascape (https://www.metascape.org/). A protein interaction network was constructed and is shown in Fig. $6 \mathrm{~d}$. The results of GO enrichment analysis showed that the functions of the regulatory enzymes mainly included cellular amino acid metabolic processes, drug metabolic processes, the metabolism of nucleotides, and nucleobase catabolic processes (Fig. 6e). Our results suggested that regulatory enzymes affected by SA were mainly involved in drug metabolism, pyrimidine metabolism, pantothenate and $\mathrm{COA}$ biosynthesis pathways, as identified by KEGG enrichment analysis (Table 4). According to these results, a schematic diagram of the altered metabolic pathways in both the serum and urine, which is shown in Fig. 7, was constructed; SA may affect these pathways to ameliorate AMI.

Validation of the potential therapeutic targets of SA According to the results of KEGG enrichment analysis of regulatory enzymes of differential metabolic markers, the regulatory enzymes involved in the top 10 pathways were selected. The regulatory enzymes related to heart disease, including ecto-5'-nucleotidase (NT5E), guanidinoacetate N-methyltransferase (GAMT), plateletderived endothelial cell growth factor (PD-ECGF) and methionine synthase (MTR), were selected for further validation. As illustrated in Fig. 8, AMI resulted in a noticeable decrease in NT5E, GAMT, and MTR expression and a significant increase in PD-ECGF expression. However, SA markedly promoted the expression of NT5E, PDECGF, and MTR and exerted no effect on GAMT expression (Fig. 8a-d). In addition, immunohistochemical analysis showed that SA significantly increased the expression of NT5E and MTR (Fig. 8e, f) and further promoted PD-ECGF expression, as evidenced by immunofluorescence staining (Fig. 8g).

SA ameliorated AMI by regulating the PI3K-Akt-NOX2 signaling pathway

As shown in Fig. 9, the Western blotting results showed that the expression of PI3K, p-Akt, and NOX2 was upregulated in AMI mice and OGD-induced cardiomyocytes. SA treatment significantly

Table 1. The parameters for assessing the model quality of OPLS-DA

\begin{tabular}{llll}
\hline Sample-mode & R2X(cum) & R2Y(cum) & Q2 \\
\hline Urine-positive & 0.691 & 0.994 & 0.971 \\
Urine-negative & 0.707 & 0.953 & 0.882 \\
Serum-positive & 0.654 & 0.976 & 0.882 \\
Serum-negative & 0.63 & 0.983 & 0.912 \\
\hline
\end{tabular}

a

OPLS-DA (Urine-Positive)

b

OPLS-DA (Urine-Negative)

C

OPLS-DA (Serum-Positive)
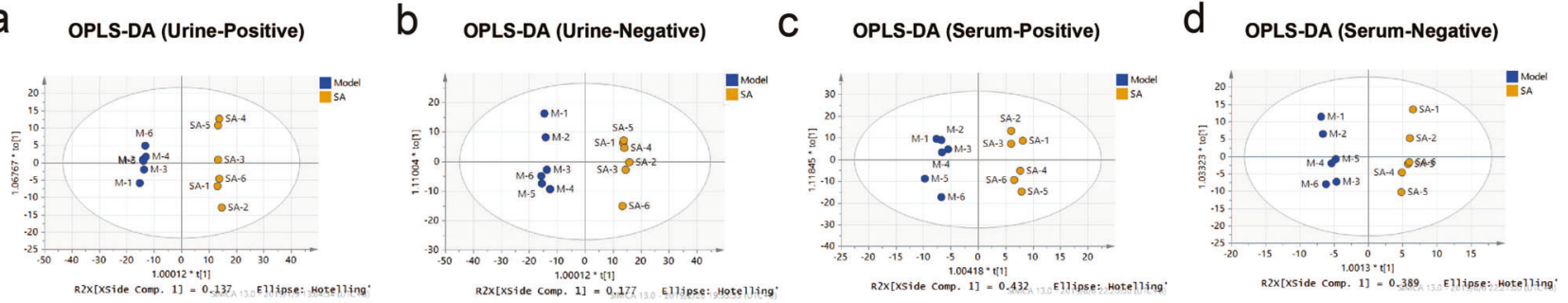

e

OPLS-DA (Urine-Positive)

f

OPLS-DA (Urine-Negative)



g

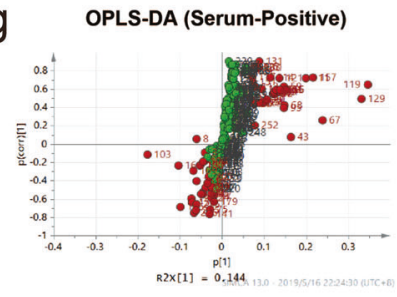

$\mathrm{h}$

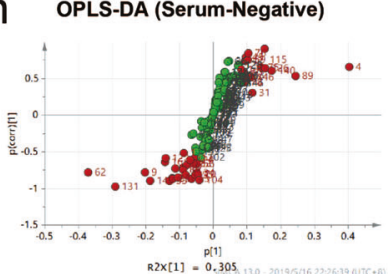

Fig. 4 Plot of OPLS-DA scores and an S-plot of the model and SA groups based on the Q-TOF system for serum and urine analysis. a-d A plot of OPLS-DA scores of the model and SA groups. e-h An S-plot of the model and SA groups. The red points represent significantly different metabolic ions 


\begin{tabular}{|c|c|c|c|c|c|c|c|c|c|}
\hline Ion mode & Identification & $m / z$ & Rt (min) & VIP & $P$-value & $\mathrm{FC}$ & Metabolic pathways & Enzymes & Genes \\
\hline \multirow[t]{24}{*}{ Positive } & N2-Acetyl-L-aminoadipate & 451.16 & 14.01 & 1.35 & $1.18 \times 10^{-9}$ & 0.52 & Lysine biosynthesis & & \\
\hline & L-isoleucyl-L-proline & 154.06 & 15.13 & 1.35 & $1.32 \times 10^{-6}$ & 0.74 & & & \\
\hline & Fructoselysine & 568.18 & 16.37 & 1.35 & $8.13 \times 10^{-8}$ & 0.69 & & & \\
\hline & 2'-O-Methyladenosine & 158.92 & 15.36 & 1.34 & $6.10 \times 10^{-11}$ & 3.52 & & & \\
\hline & 1-Methylguanosine & 428.22 & 11.10 & 1.34 & $7.37 \times 10^{-9}$ & 0.56 & & & \\
\hline & L-Valine & 144.10 & 14.92 & 1.34 & $1.63 \times 10^{-8}$ & 1.53 & $\begin{array}{l}\text { Valine, leucine and isoleucine } \\
\text { biosynthesis; } \\
\text { Propanoate metabolism; } \\
\text { Aminoacyl-tRNA biosynthesis; } \\
\text { Pantothenate and CoA biosynthesis }\end{array}$ & $\begin{array}{l}\text { Propionyl-CoA carboxylase beta } \\
\text { chain, mitochondrial; } \\
\text { Catechol O-methyltransferase }\end{array}$ & $\begin{array}{l}\text { PCCB; } \\
\text { COMT }\end{array}$ \\
\hline & L-prolyl-L-proline & 538.19 & 15.97 & 1.33 & $2.68 \times 10^{-7}$ & 0.76 & & & \\
\hline & N-Acetylhistamine & 143.12 & 7.78 & 1.33 & $8.25 \times 10^{-7}$ & 0.76 & & $\begin{array}{l}\text { Glutaminyl-peptide } \\
\text { cyclotransferase }\end{array}$ & QPCT \\
\hline & Creatinine & 149.11 & 4.66 & 1.33 & $2.00 \times 10^{-6}$ & 0.55 & Arginine and proline metabolism & & \\
\hline & $\begin{array}{l}\text { N-Methyl-4-pyridone-3- } \\
\text { carboxamide }\end{array}$ & 125.10 & 3.33 & 1.33 & $1.14 \times 10^{-5}$ & 0.84 & & Aldehyde oxidase & AOX1 \\
\hline & L-prolyl-L-glycine & 258.11 & 15.98 & 1.33 & $6.88 \times 10^{-7}$ & 0.69 & & & \\
\hline & L-Methionine & 150.06 & 14.32 & 1.33 & $8.88 \times 10^{-5}$ & 0.90 & $\begin{array}{l}\text { Cysteine and methionine } \\
\text { metabolism; } \\
\text { Aminoacyl-tRNA biosynthesis }\end{array}$ & $\begin{array}{l}\text { Methionine synthase; } \\
\text { Methylenetetrahydrofolate } \\
\text { reductase }\end{array}$ & $\begin{array}{l}\text { MTR; } \\
\text { MTHFR }\end{array}$ \\
\hline & Xanthurenic acid & 414.30 & 3.07 & 1.32 & $1.06 \times 10^{-8}$ & 2.03 & Tryptophan metabolism & $\begin{array}{l}\text { HemK methyltransferase family } \\
\text { member } 1\end{array}$ & HEMK1 \\
\hline & L-Isoleucine & 396.16 & 4.26 & 1.32 & $4.78 \times 10^{-7}$ & 0.51 & $\begin{array}{l}\text { Valine, leucine and isoleucine } \\
\text { biosynthesis; } \\
\text { Aminoacyl-tRNA biosynthesis }\end{array}$ & $\begin{array}{l}\text { Branched-chain-amino-acid } \\
\text { aminotransferase, cytosolic; } \\
\text { Branched-chain-amino-acid } \\
\text { aminotransferase, mitochondrial }\end{array}$ & $\begin{array}{l}\text { BCAT1; } \\
\text { BCAT2 }\end{array}$ \\
\hline & Fibrin & 60.08 & 5.21 & 1.32 & $3.57 \times 10^{-9}$ & 1.77 & & & \\
\hline & Taurine & 162.11 & 14.70 & 1.32 & $3.14 \times 10^{-9}$ & 1.58 & $\begin{array}{l}\text { Taurine and hypotaurine metabolism; } \\
\text { Nitrogen metabolism }\end{array}$ & $\begin{array}{l}\text { Bile acid-CoA:amino acid N- } \\
\text { acyltransferase; } \\
\text { Glutamate decarboxylase } 2\end{array}$ & $\begin{array}{l}\text { BAAT; } \\
\text { GAD2 }\end{array}$ \\
\hline & Glycylprolylhydroxyproline & 596.30 & 16.81 & 1.31 & $1.65 \times 10^{-6}$ & 0.75 & & & \\
\hline & Prolylhydroxyproline & 281.09 & 15.98 & 1.30 & $1.44 \times 10^{-2}$ & 0.96 & & & \\
\hline & Deoxyguanosine & 352.10 & 13.46 & 1.30 & $6.47 \times 10^{-7}$ & 2.80 & Purine metabolism & $\begin{array}{l}\text { 5'-nucleotidase; } \\
\text { Deoxyguanosine kinase, } \\
\text { mitochondrial }\end{array}$ & $\begin{array}{l}\text { NT5E; } \\
\text { DGUOK }\end{array}$ \\
\hline & Isovalerylsarcosine & 284.01 & 2.23 & 1.26 & $7.96 \times 10^{-4}$ & 0.63 & & Glycine N-acyltransferase & GLYAT \\
\hline & 3'-O-Methylguanosine & 331.14 & 11.22 & 1.25 & $1.59 \times 10^{-4}$ & 0.63 & & & \\
\hline & Spermidine & 323.07 & 15.48 & 1.21 & $1.30 \times 10^{-2}$ & 0.89 & $\begin{array}{l}\text { Arginine and proline metabolism; } \\
\text { beta-Alanine metabolism }\end{array}$ & $\begin{array}{l}\text { Spermine synthase; } \\
\text { 3-ketoacyl-CoA thiolase, } \\
\text { mitochondrial; } \\
\text { Thioredoxin reductase 1, } \\
\text { cytoplasmic }\end{array}$ & $\begin{array}{l}\text { SMS; } \\
\text { ACAA2; } \\
\text { TXNRD1 }\end{array}$ \\
\hline & Thymine & 127.05 & 6.72 & 1.18 & $1.61 \times 10^{-5}$ & 1.65 & Pyrimidine metabolism & $\begin{array}{l}\text { Dihydropyrimidine } \\
\text { dehydrogenase [NADP }(+)] ; \\
\text { Thymidine phosphorylase }\end{array}$ & $\begin{array}{l}\text { DPYD; } \\
\text { TYMP }\end{array}$ \\
\hline & 5-Methylcytidine & 516.21 & 10.43 & 1.17 & $1.58 \times 10^{-3}$ & 0.66 & & & \\
\hline \multirow[t]{10}{*}{ Negative } & 4-Phospho-L-aspartate & 324.96 & 3.07 & 1.41 & $2.20 \times 10^{-12}$ & 3.04 & $\begin{array}{l}\text { Glycine, serine and threonine } \\
\text { metabolism; } \\
\text { Lysine biosynthesis; } \\
\text { Cysteine and methionine metabolism }\end{array}$ & & \\
\hline & $\begin{array}{l}\text { Beta- } \\
\text { Glycerophosphoric acid }\end{array}$ & 216.93 & 15.38 & 1.38 & $2.47 \times 10^{-10}$ & 2.47 & & & \\
\hline & $m$-Chlorohippuric acid & 147.04 & 3.10 & 1.38 & $7.11 \times 10^{-9}$ & 1.94 & & & \\
\hline & Glycylprolylhydroxyproline & 321.13 & 16.86 & 1.37 & $6.11 \times 10^{-6}$ & 0.60 & & & \\
\hline & Homoserine & 259.09 & 15.63 & 1.37 & $5.93 \times 10^{-7}$ & 0.50 & $\begin{array}{l}\text { Glycine, serine and threonine } \\
\text { metabolism; } \\
\text { Lysine biosynthesis; } \\
\text { Cysteine and methionine } \\
\text { metabolism; } \\
\text { Sulfur metabolism }\end{array}$ & & \\
\hline & Guanidineacetic acid & 96.97 & 15.33 & 1.36 & $9.22 \times 10^{-9}$ & 1.85 & $\begin{array}{l}\text { Glycine, serine and threonine } \\
\text { metabolism; } \\
\text { Arginine and proline metabolism }\end{array}$ & $\begin{array}{l}\text { Guanidinoacetate N- } \\
\text { methyltransferase; } \\
\text { Glycine amidinotransferase, } \\
\text { mitochondrial }\end{array}$ & $\begin{array}{l}\text { GAMT; } \\
\text { GATM }\end{array}$ \\
\hline & D-Glutamine & 145.06 & 16.00 & 1.36 & $4.63 \times 10^{-5}$ & 0.71 & $\begin{array}{l}D \text {-Glutamine and } D \text {-glutamate } \\
\text { metabolism }\end{array}$ & $\begin{array}{l}\text { Glutaminase liver isoform, } \\
\text { mitochondrial; } \\
\text { Glutaminase kidney isoform, } \\
\text { mitochondrial }\end{array}$ & $\begin{array}{l}\text { GLS2; } \\
\text { GLS }\end{array}$ \\
\hline & L-Iditol & 306.09 & 14.83 & 1.36 & $1.00 \times 10^{-5}$ & 0.48 & & Sorbitol dehydrogenase & SORD \\
\hline & Ureidoisobutyric acid & 104.04 & 16.07 & 1.36 & $1.07 \times 10^{-5}$ & 0.74 & Pyrimidine metabolism & $\begin{array}{l}\text { Dihydropyrimidinase; } \\
\text { Beta-ureidopropionase }\end{array}$ & $\begin{array}{l}\text { DPYS; } \\
\text { UPB1 }\end{array}$ \\
\hline & Tyramine glucuronide & 312.11 & 16.72 & 1.34 & $3.03 \times 10^{-7}$ & 1.60 & & $\begin{array}{l}\text { UDP- } \\
\text { glucuronosyltransferase } 2 \mathrm{~B} 28\end{array}$ & UGT2B28 \\
\hline
\end{tabular}




\begin{tabular}{|c|c|c|c|c|c|c|c|c|c|}
\hline Ion mode & Identification & $m / z$ & Rt (min) & VIP & $P$-value & FC & Metabolic pathways & Enzymes & Genes \\
\hline & Galactonic acid & 299.11 & 15.13 & 1.34 & $1.80 \times 10^{-3}$ & 0.80 & \multirow[t]{2}{*}{ Galactose metabolism } & & \\
\hline & $\begin{array}{l}\text { 5-Hydroxy-2-oxo-4-ureido- } \\
\text { 2,5-dihydro-1H-imidazole-5- } \\
\text { carboxylate }\end{array}$ & 176.00 & 1.68 & 1.34 & $7.15 \times 10^{-5}$ & 0.72 & & $\begin{array}{l}\text { Putative 2-oxo-4-hydroxy-4- } \\
\text { carboxy-5-ureidoimidazoline } \\
\text { decarboxylase }\end{array}$ & PRHOXNB \\
\hline & Uric acid & 256.06 & 14.02 & 1.33 & $3.34 \times 10^{-4}$ & 0.77 & Purine metabolism & $\begin{array}{l}\text { Xanthine dehydrogenase/ } \\
\text { oxidase }\end{array}$ & $\mathrm{XDH}$ \\
\hline & Creatine & 169.06 & 15.28 & 1.32 & $3.28 \times 10^{-9}$ & 1.67 & $\begin{array}{l}\text { Glycine, serine and threonine } \\
\text { metabolism; } \\
\text { Arginine and proline metabolism }\end{array}$ & $\begin{array}{l}\text { Guanidinoacetate } \mathrm{N} \text { - } \\
\text { methyltransferase; } \\
\text { Creatine kinase S-type, } \\
\text { mitochondrial }\end{array}$ & $\begin{array}{l}\text { GAMT; } \\
\text { CKMT2 }\end{array}$ \\
\hline & N-Glycolylneuraminic acid & 324.10 & 15.48 & 1.32 & $4.62 \times 10^{-4}$ & 0.79 & $\begin{array}{l}\text { Amino sugar and nucleotide sugar } \\
\text { metabolism }\end{array}$ & $\begin{array}{l}\mathrm{N} \text {-acylneuraminate } \\
\text { cytidylyltransferase }\end{array}$ & CMAS \\
\hline & Citric acid & 279.04 & 4.46 & 1.31 & $3.87 \times 10^{-3}$ & 0.83 & \multirow[t]{2}{*}{ Citrate cycle (TCA cycle) } & $\begin{array}{l}\text { ATP-citrate synthase; } \\
\text { Citrate synthase, mitochondrial }\end{array}$ & $\begin{array}{l}\text { ACLY; } \\
\text { CS }\end{array}$ \\
\hline & Tetrahydropteridine & 263.04 & 15.00 & 1.31 & $1.88 \times 10^{-3}$ & 0.81 & & $\begin{array}{l}\text { Dihydropteridine reductase; } \\
\text { Inositol-tetrakisphosphate } 1 \text { - } \\
\text { kinase }\end{array}$ & $\begin{array}{l}\text { QDPR; } \\
\text { ITPK1 }\end{array}$ \\
\hline & $D$-Tagatose & 220.08 & 14.19 & 1.30 & $7.76 \times 10^{-4}$ & 0.78 & \multicolumn{3}{|l|}{ Galactose metabolism } \\
\hline & $\begin{array}{l}\text { Deoxyadenosine } \\
\text { monophosphate }\end{array}$ & 325.11 & 12.40 & 1.30 & $1.46 \times 10^{-4}$ & 0.57 & Purine metabolism & $\begin{array}{l}5^{\prime} \text {-nucleotidase; } \\
5^{\prime}\left(3^{\prime}\right) \text {-deoxyribonucleotidase, } \\
\text { mitochondrial }\end{array}$ & $\begin{array}{l}\text { NT5E; } \\
\text { NT5M }\end{array}$ \\
\hline & $D$-Serine & 225.06 & 16.13 & 1.19 & $5.40 \times 10^{-6}$ & 1.39 & $\begin{array}{l}\text { Glycine, serine and threonine } \\
\text { metabolism }\end{array}$ & $\begin{array}{l}\text { Phosphoserine phosphatase; } \\
\text { Serine racemase }\end{array}$ & $\begin{array}{l}\text { PSPH; } \\
\text { SRR }\end{array}$ \\
\hline & Paraxanthine & 222.10 & 14.27 & 1.17 & $2.82 \times 10^{-3}$ & 0.49 & Caffeine metabolism & $\begin{array}{l}\text { Arylamine } \mathrm{N} \text {-acetyltransferase } 1 \\
\text { Xanthine dehydrogenase/ } \\
\text { oxidase }\end{array}$ & $\begin{array}{l}\text { NAT1; } \\
\text { XDH }\end{array}$ \\
\hline & Uridine & 367.07 & 13.67 & 1.15 & $5.19 \times 10^{-4}$ & 5.26 & \multirow[t]{2}{*}{ Pyrimidine metabolism } & $\begin{array}{l}5^{\prime} \text {-nucleotidase; } \\
5^{\prime}\left(3^{\prime}\right) \text {-deoxyribonucleotidase, } \\
\text { mitochondrial }\end{array}$ & $\begin{array}{l}\text { NT5E; } \\
\text { NT5M }\end{array}$ \\
\hline & Dihydroferulic acid 4-sulfate & 335.05 & 14.08 & 1.03 & $4.28 \times 10^{-4}$ & 1.74 & & & \\
\hline & $\begin{array}{l}\text { 4-Imidazolone-5- } \\
\text { propionic acid }\end{array}$ & 257.08 & 15.42 & 1.01 & $2.23 \times 10^{-4}$ & 1.37 & Histidine metabolism & $\begin{array}{l}\text { Urocanate hydratase; } \\
\text { Probable imidazolonepropionase }\end{array}$ & $\begin{array}{l}\text { UROC1; } \\
\text { AMDHD1 }\end{array}$ \\
\hline
\end{tabular}

Table 3. Statistical analysis of 14 differential metabolites from the comparison of model versus SA in serum

\begin{tabular}{|c|c|c|c|c|c|c|c|c|c|}
\hline Ion mode & Identification & $m / z$ & $\mathrm{Rt}(\min )$ & VIP & $P$-value & FC & Metabolic pathways & Enzymes & Genes \\
\hline \multirow[t]{2}{*}{ Positive } & Palmitic acid & 279.23 & 13.25 & 2.07 & $5.74 \times 10^{-6}$ & 0.66 & $\begin{array}{l}\text { Fatty acid elongation in } \\
\text { mitochondria; } \\
\text { Fatty acid biosynthesis }\end{array}$ & Fatty acid synthase & FASN \\
\hline & Dityrosine & 219.03 & 0.64 & 1.20 & $1.26 \times 10^{-3}$ & 1.25 & & & \\
\hline \multirow[t]{12}{*}{ Negative } & 5-Oxo-ETE/5-KETE & 295.23 & 13.25 & 1.95 & $1.06 \times 10^{-6}$ & 0.63 & & & \\
\hline & Glyceraldehyde & 116.91 & 2.23 & 1.75 & $6.56 \times 10^{-6}$ & 1.61 & & Aldose reductase & AKR1B1 \\
\hline & L-Lactic acid & 117.04 & 1.31 & 1.68 & $4.88 \times 10^{-5}$ & 1.52 & $\begin{array}{l}\text { Propanoate metabolism; } \\
\text { Glycolysis or Gluconeogenesis; } \\
\text { Pyruvate metabolism }\end{array}$ & L-lactate dehydrogenase A-like $6 \mathrm{~A}$ & LDHAL6A \\
\hline & Adipate semialdehyde & 160.90 & 2.14 & 1.55 & $1.14 \times 10^{-3}$ & 2.07 & & Alcohol dehydrogenase $[\mathrm{NADP}(+)]$ & AKR1A1 \\
\hline & $p$-Cresol sulfate & 187.01 & 7.91 & 1.48 & $3.93 \times 10^{-3}$ & 2.77 & & & \\
\hline & Orotic acid & 128.03 & 0.72 & 1.44 & $1.54 \times 10^{-4}$ & 1.46 & Pyrimidine metabolism & $\begin{array}{l}\text { Dihydroorotate dehydrogenase (quinone), } \\
\text { mitochondrial; } \\
\text { Uridine } 5^{\prime} \text {-monophosphate synthase }\end{array}$ & $\begin{array}{l}\text { DHODH; } \\
\text { UMPS }\end{array}$ \\
\hline & $\begin{array}{l}\text { Sphinganine-1- } \\
\text { phosphate }\end{array}$ & 638.35 & 12.00 & 1.14 & $1.60 \times 10^{-2}$ & 1.60 & & $\begin{array}{l}\text { Lipid phosphate phosphohydrolase } 1 ; \\
\text { Lipid phosphate phosphohydrolase } 2\end{array}$ & $\begin{array}{l}\text { PPAP2A; } \\
\text { PPAP2C }\end{array}$ \\
\hline & LysoPE(0:0/18:0) & 591.37 & 12.75 & 1.62 & $6.61 \times 10^{-4}$ & 0.76 & & $\begin{array}{l}\text { Ectonucleotide pyrophosphatase/phosphodiesterase } \\
\text { family member } 2\end{array}$ & ENPP2 \\
\hline & $\begin{array}{l}\text { LysoPE(22:4 } \\
(7 Z, 10 Z, 13 Z, 16 Z) / 0: 0)\end{array}$ & 452.29 & 12.58 & 1.59 & $2.88 \times 10^{-4}$ & 1.29 & & & \\
\hline & LysoPE(20:0/0:0) & 620.31 & 15.26 & 1.43 & $8.14 \times 10^{-3}$ & 0.66 & & & \\
\hline & LysoPE(18:2(9Z,12Z)/0:0) & 524.29 & 12.33 & 1.15 & $1.65 \times 10^{-2}$ & 1.31 & & & \\
\hline & LysoPE(18:1(11Z)/0:0) & 538.33 & 12.08 & 1.04 & $4.23 \times 10^{-6}$ & 1.21 & & & \\
\hline
\end{tabular}

further increased the expression of PI3K and p-Akt and downregulated the expression of NOX2.

\section{DISCUSSION}

In the present study, we confirmed the efficacy of SA in AMIinjured mice and OGD-injured cardiomyocytes, as evidenced by the decrease in infarct size and the most common biomarkers for myocardial ischemia, such as LDH, CK, CTn-I, CRP, and TNF-a. In addition, echocardiography is clinically applied to evaluate cardiac function and structure [21]. LVEF and LVFS measurements are used as key markers of contractile capabilities both in basic and clinical studies. The main function of the heart in the circulatory system is to pump blood to meet the needs of metabolism. Thus, SV is also a basic indicator used to evaluate cardiac function [22]. Our present results demonstrated that treatment with SA preserved cardiac function and improved cardiac tissue damage and fibrosis in mice subjected to AMI injury. These positive effects 




Fig. 5 Heatmap of the 49 differentially regulated endogenous metabolites in the serum and urine between the model and SA groups

of SA were associated with the suppression of cardiomyocyte apoptosis. Accumulating pharmacological studies have suggested that the loss of cardiomyocytes as a result of apoptosis is essential in various heart diseases and inevitably contributes to heart failure [23]. Intervening in the apoptotic process could attenuate the loss of cardiomyocytes, alleviate cardiac injury and ultimately inhibit the occurrence and development of AMI injury.

In addition, the HPLC-Q-TOF/MS metabolomics approach was selected to explore metabolic changes in mice with AMI and uncover the treatment mechanism of SA. Forty-eight differentially regulated metabolites were found between the model group and SA group. SA markedly increased the levels of fructoselysine, 1-methylguanosine, $\mathrm{N}$-acetylhistamine, creatinine and L-isoleucine, $D$-glutamine, and citric acid compared to those in AMI mice. Some studies have shown that later-stage or advanced-stage glycation processes involve the degradation of fructoselysine and the glycation of proteins by methylglyoxal to form advanced glycation end products, which contribute to the pathogenesis of vascular complications of diabetes [24]. Additionally, 1-methylguanosine was identified as a marker that predicts the development of nephropathy in T2DM patients [25]. Meanwhile, in the general population, moderately elevated plasma creatinine and $L$-isoleucine levels are correlated with an increased risk of myocardial infarction, ischemic heart disease and early death $[26,27]$. In addition, glutamine has been found to maintain cardiac function perioperatively and promote glycogen metabolism by enhancing mitochondrial function and stimulating mTORC1 [28].
Citric acid is an essential metabolite involved in the tricarboxylic acid cycle (TCA) cycle. The TCA cycle is the ultimate metabolic pathway of the three major nutrients (carbohydrates, lipids, amino acids), and it is also an important hub of the metabolic link between carbohydrates, lipids and amino acids [29].

The levels of xanthurenic acid, $D$-serine and thymine in the SA group were lower than those in the AMI group. Xanthurenic acid is a biomarker related to the kynurenine pathway. In patients with suspected stable angina pectoris, elevated levels of plasma kynurenines predict an increased risk of acute myocardial infarction, and risk estimates are generally stronger in subgroups with evidence of impaired glucose homeostasis [30]. Furthermore, atherosclerosis is the underlying cause of most myocardial infarction and ischemic stroke episodes. Recent studies have suggested that there is a direct relationship between $D$-serine and intima media thickness, which is an early sign of atherosclerosis [31]. Moreover, larger cytosine-thymine-guanine expansions have been reported to be associated with a higher rate of conduction disease progression and a trend toward an increased risk of cardiac events [32].

Subsequently, the pathways of differential metabolites and regulatory enzymes were further analyzed, and we found that SA mainly regulated metabolic pathways, including the glycine, serine and threonine metabolism, lysine biosynthesis, pyrimidine metabolism, arginine and proline metabolism, cysteine and methionine metabolism, and valine, leucine and isoleucine biosynthesis pathways. The glycine, serine and threonine metabolism pathway 
a

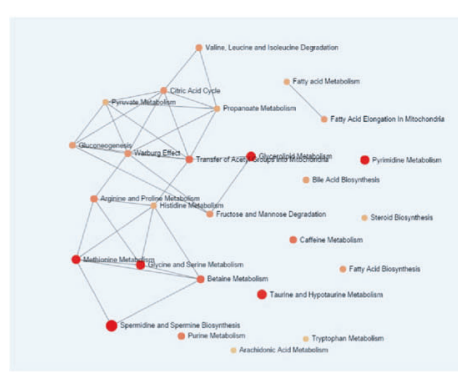

\section{b}



C

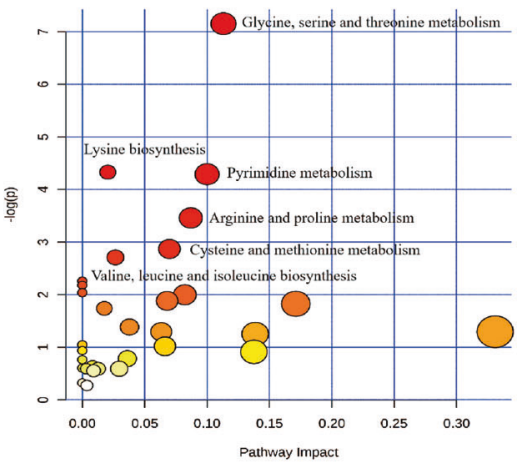

d

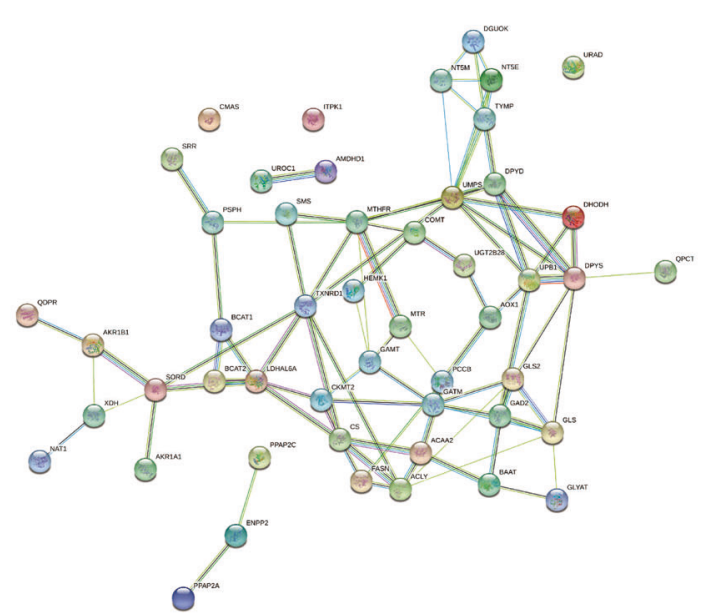

e

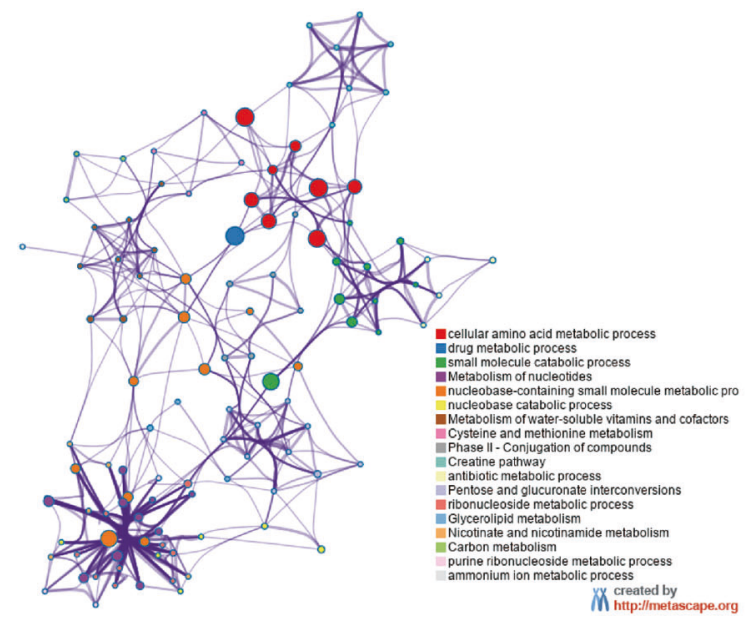

Fig. 6 Enrichment analysis of metabolic pathways and related regulatory enzymes. a Differential metabolite network map. $\mathbf{b}$ Overview of the pathways related to the differentially regulated endogenous metabolites. c Summary of pathway analysis by MetPA. d Regulatory protein network map. e Regulatory enzyme GO enrichment analysis results
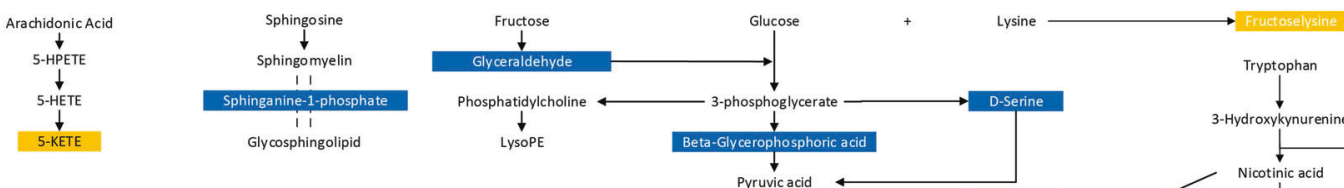

Glycosphingolipid
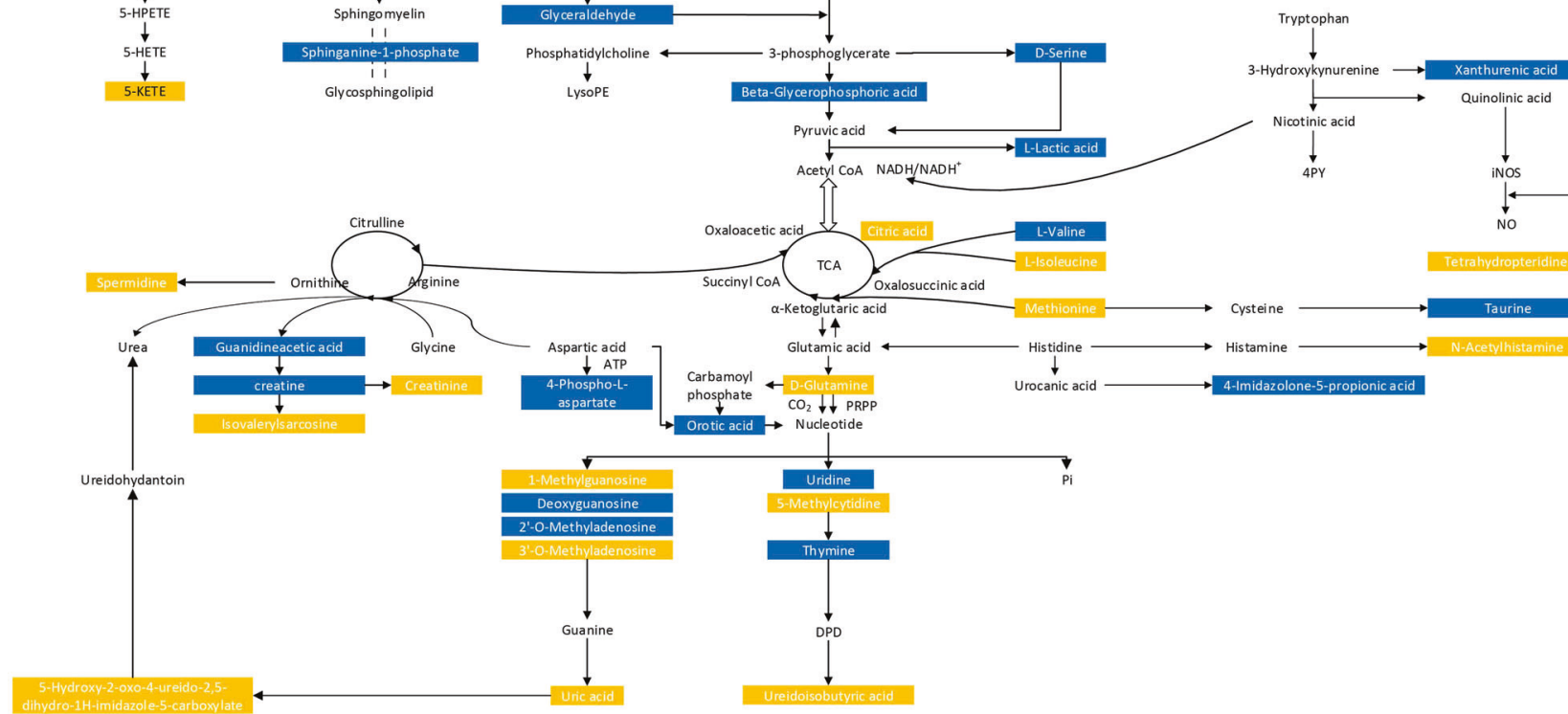

$\underset{+}{\mathrm{CO}_{2} \downarrow \downarrow \text { PRPP }}$

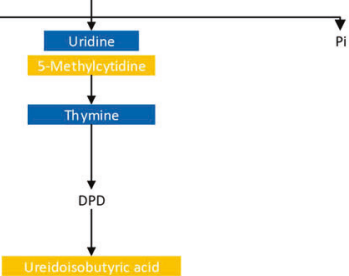

Fig. 7 Metabolic network of the significantly changed endogenous metabolites in both the serum and urine. The metabolites that were elevated in the SA group compared with the model group are represented by blue, and the reduced metabolites are represented by yellow 




supplies important energy metabolism precursors for the citrate cycle. Previous studies have shown that glycine and serine can reduce myocardial inflammation by activating glycine receptors and indirectly inhibit collagen production in cardiac fibroblasts, ultimately inhibiting myocardial fibrosis [33]. In addition, impairments in cardiac energy metabolism and mitochondrial function are intricately correlated with cardiac dysfunction. Mitochondrial dysfunction contributes to increased oxidative stress, cell death and myocardial remodeling. Recent developments suggest that mitochondrial protein lysine biosynthesis modulates the sensitivity of the heart to stress and hence the propensity for heart failure [34]. Furthermore, during arginine and proline metabolism, creatine, which reacts with ATP during the catalysis of creatine kinase, is broken down into phosphocreatine and creatinine. Under conditions of AMI, the level of creatine is depressed significantly. Cardiac ischemia and reperfusion seem to shift arginine metabolism from forming nitric oxide to forming polyamine, which may limit functional recovery after reperfusion [35]. In addition, the cysteine and methionine metabolic pathways are also widely associated with the pathogenesis of myocardial infarction, atherosclerosis and other cardiovascular diseases [36-38].

To further explore the potential targets of $\mathrm{SA}$ in inducing cardioprotection, NT5E, GAMT, PD-ECGF, and MTR were identified and primarily verified in the present study. NT5E is the key enzyme that controls the degradation of adenine nucleotides into adenosine via the enzymatic dephosphorylation of AMP in 
a

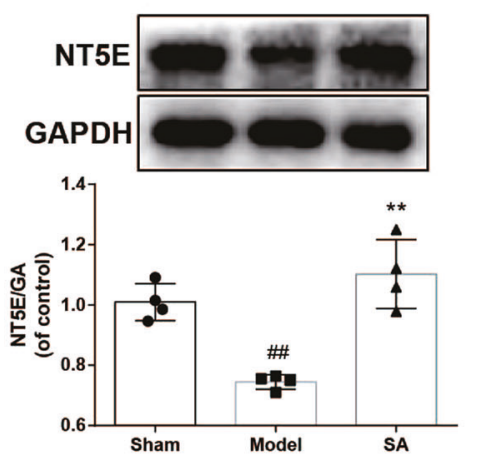

d

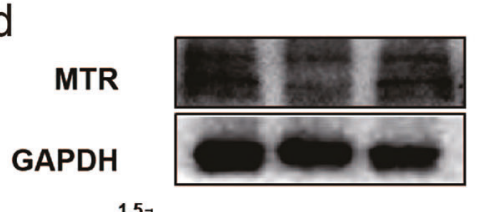

b



C

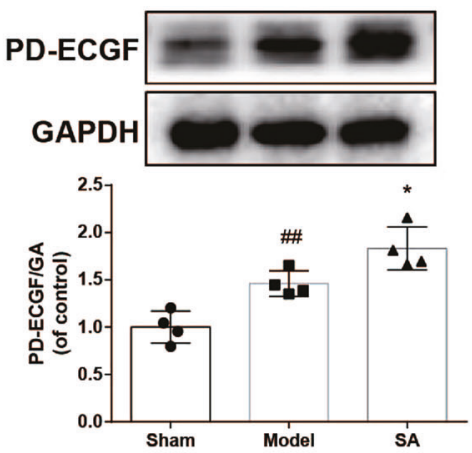

e



f

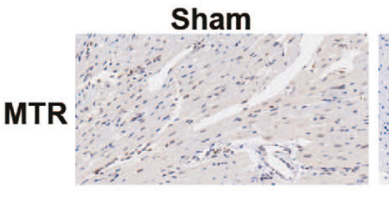

Model

SA
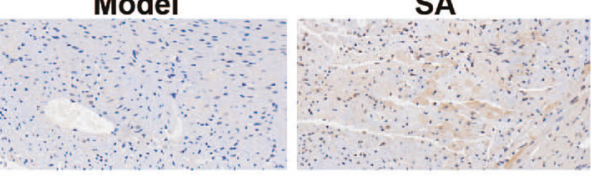

g
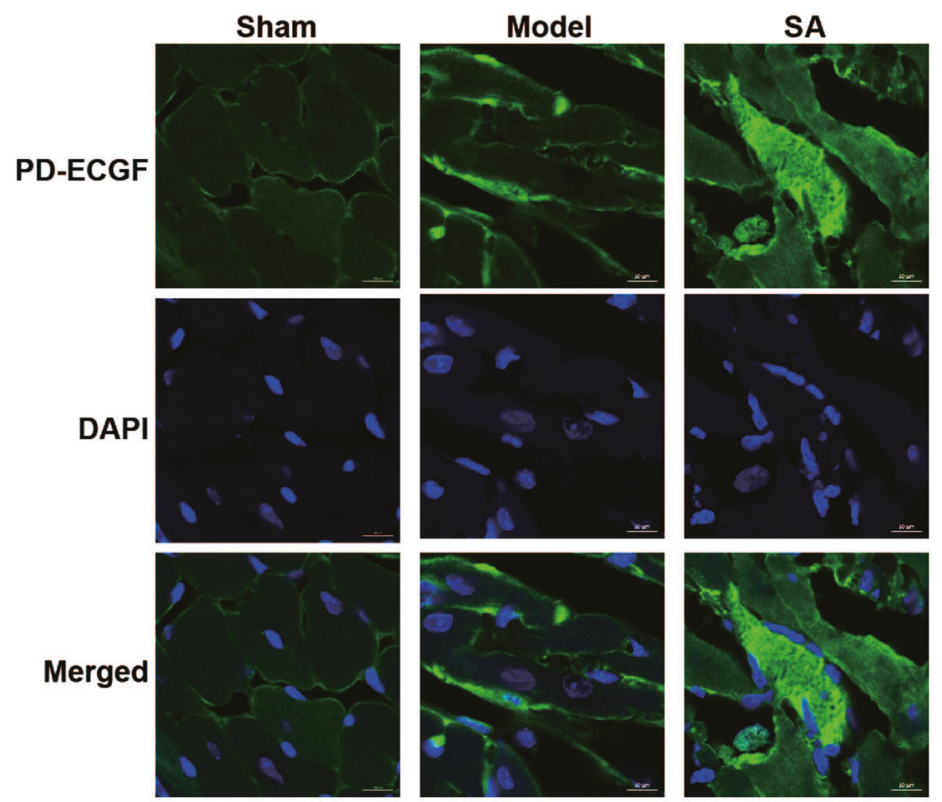

Fig. 8 Changes in protein expression in the heart tissue of AMI mice after $24 \mathrm{~h}$. The expression of NT5E (a), GAMT (b), PD-ECGF (c), and MTR (d) was detected using Western blot analysis. The expression of NT5E (e) and MTR (f) was detected using immunohistochemistry. The expression of PD-ECGF was measured by immunofluorescence staining $(\mathbf{g})$. The results are presented as the mean \pm SEM. ${ }^{\# \#} P<0.01$ vs. the control group, ${ }^{*} P<0.05,{ }^{*} P<0.01$ vs. the model group

the ischemic myocardium. Adenosine, a degradation substance of ATP, exerts an essential role in regulating cardiac contractility, coronary vascular tone, and cardiac substrate utilization [39-41]. Recent studies have demonstrated that oxidative stress may cause the inactivation of NT5E and decrease the concentration of adenosine in the rat heart [42]. Our results indicated that AMI inhibited the expression of NT5E while SA markedly reversed this suppression. Moreover, creatine is mainly produced through two essential chemical reactions and a second step catalyzed by GAMT. GAMT knockout mice show increased susceptibility to ischemia/reperfusion injury, which is reflected by changes in high-energy phosphate metabolism [43]. Our results indicated that SA had no effect on the promotion of GAMT expression. In addition, previous studies have documented an increase in the expression of the angiogenic protein PD-ECGF in a rat model of MI [44]. In our present study, SA further promoted PD-ECGF 
a
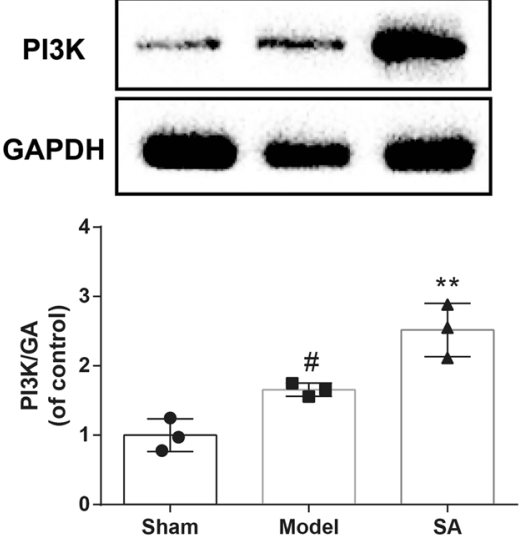

d
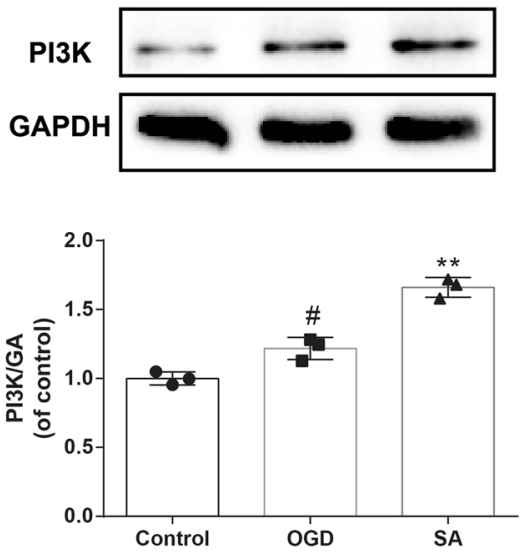

$b$
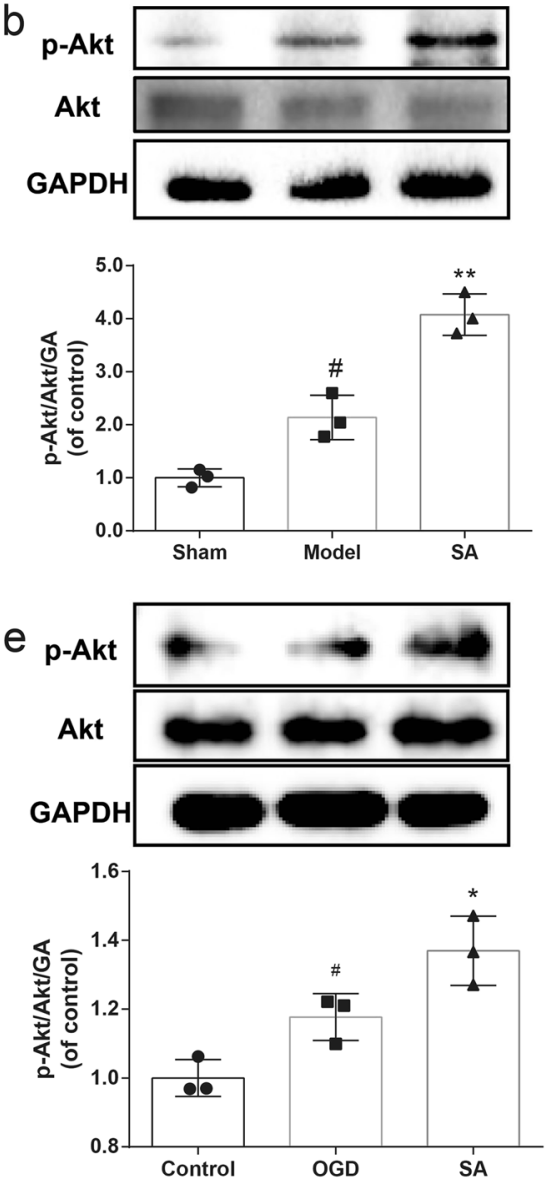

C
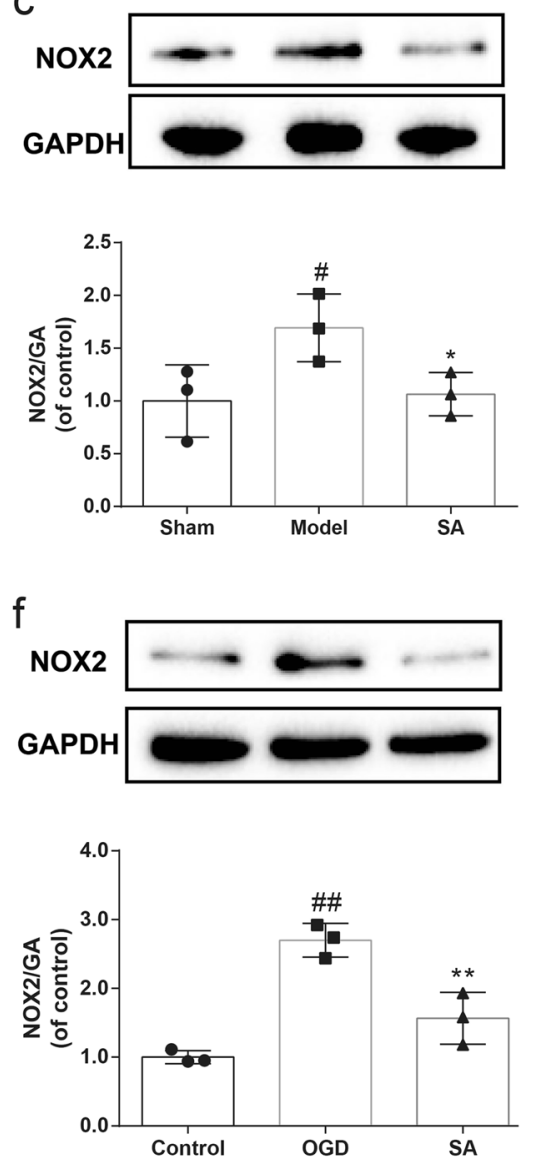

Fig. 9 The effect of SA on the PI3K-Akt-NOX2 signaling pathway in AMI mice and OGD-induced cardiomyocytes. The expression of PI3K (a), Akt, p-Akt (b), and NOX2 (c) in AMl mice was detected using Western blot analysis. The expression of PI3K (d), Akt, p-Akt (e) and NOX2 (f) in OGDinduced cardiomyocytes was determined using Western blot analysis. ${ }^{\#} P<0.05,{ }^{\# \#} P<0.01$ vs. the control group, ${ }^{*} P<0.05,{ }^{* *} P<0.01$ vs. the model group

expression, which is also a potent peptide with anti-apoptotic activity. Simultaneously, SA promoted the expression of MTR, which is one of the key enzymes in folate metabolism. Several studies have suggested that MTR deficiency can increase the risk of congenital heart disease [45]. Based on the above results, it can be reasonably speculated that SA might attenuate AMIinduced cardiomyocyte apoptosis through the promotion of NT5E, PD-ECGF, and MTR expression.

Furthermore, we explored the potential pathways regulated by SA. Previous investigations have demonstrated that NT5E regulates the production of adenosine and that adenosine modulates vascular tone via PI3K/Akt signaling cascade-mediated eNOS activation and NO production [46]. In our present study, we found that SA promoted the expression of NT5E, while SA was found to facilitate $\mathrm{PI} 3 \mathrm{~K} / \mathrm{Akt}$ activation and inhibit the expression of NOX2. These findings suggest that the cardioprotective effect of SA is at least partially mediated by the PI3K/Akt-NOX2 signaling pathway.

\section{CONCLUSION}

In summary, for the first time we revealed the endogenous metabolic small molecules and metabolic pathways regulated by SA in AMI through nontargeted metabonomics and the construction of a regulatory metabolic network map. Furthermore, several potential new targets of SA, such as NT5E, PD-ECGF, and MTR, were identified and verified, and SA was shown to exert cardioprotective effects against AMI, at least in part through the $\mathrm{PI3K} /$ Akt-NOX2 signaling pathway.

\section{ACKNOWLEDGEMENTS}

This research work was supported by the National Natural Science Foundation of China (No. 81973506, 81603328, 81774150, and 81573719), the Natural Science Foundation of Jiangsu Province (BK20160761), the China Postdoctoral Science Foundation (2016M600456 and 2017T100425), and the "Double First-Class" University Project (CPU2018GF06 and CPU2018GF07).

\section{AUTHOR CONTRIBUTIONS}

FL and BYY conceived the study. QL and GYY performed the metabolomic analysis. $\mathrm{QL}, \mathrm{HW}$, and ZLL established the animal model and performed the in vivo experiments. GYY and HW collected the samples. QL, GYY, and HW interpreted the data. QL, JPK, and FL aided in the data analysis and wrote the paper. All authors read and approved the final paper.

\section{ADDITIONAL INFORMATION}

The online version of this article (https://doi.org/10.1038/s41401-020-0377-7) contains supplementary material, which is available to authorized users.

Competing interests The authors declare no competing interests.

\section{REFERENCES}

1. Roth GA, Johnson C, Abajobir A, Abd-Allah F, Abera SF, Abyu G, et al. Global, regional, and national burden of cardiovascular diseases for 10 causes, 1990 to 2015. J Am Coll Cardiol. 2017;70:1-25.

2. Shimokawa H, Yasuda S. Myocardial ischemia: current concepts and future perspectives. J Cardiol. 2008;52:67-78. 
3. Kalogeris T, Baines CP, Krenz M, Korthuis RJ. Cell biology of ischemia/reperfusion injury. Int Rev Cell Mol Biol. 2012;298:229-317.

4. Wang YH, Qiu C, Wang DW, Hu ZF, Yu BY, Zhu DN, et al. Identification of multiple constituents in the traditional Chinese medicine formula Sheng-Mai San and rat plasma after oral administration by HPLC-DAD-MS/MS. J Pharm Biomed Anal. 2011;54:1110-27.

5. Konishi T. Brain oxidative stress as basic target of antioxidant traditional oriental medicines. Neurochem Res. 2009;34:711-6.

6. Li F, Tan YS, Chen HL, Yan Y, Zhai KF, Li DP, et al. Identification of schisandrin as a vascular endothelium protective component in YiQiFuMai powder injection using HUVECs binding and HPLC-DAD-Q-TOF-MS/MS analysis. J Pharmacol Sci. 2015;129:1-8.

7. Cheng HY, Hsieh MT, Wu CR, Tsai FH, Lu TC, Hsieh CC, et al. Schizandrin protects primary cultures of rat cortical cells from glutamate-induced excitotoxicity. J Pharmacol Sci. 2008;107:21-31.

8. Hu D, Cao Y, He R, Han N, Liu Z, Miao L, et al. Schizandrin, an antioxidant lignan from Schisandra chinensis, ameliorates $A \beta$ 1-42-induced memory impairment in mice. Oxid Med Cell Longev. 2012;1:1-25.

9. Park SY, Park DJ, Kim YH, Kim Y, Kim SG, Shon KJ, et al. Upregulation of heme oxygenase-1 via PI3K/Akt and Nrf-2 signaling pathways mediates the antiinflammatory activity of Schisandrin in Porphyromonas gingivalis LPS-stimulated macrophages. Immunol Lett. 2011;139:93-101.

10. Li F, Fan X, Zhang Y, Pang L, Ma X, Song M, et al. Cardioprotection by combination of three compounds from ShengMai preparations in mice with myocardial ischemia/reperfusion injury through AMPK activation-mediated mitochondrial fission. Sci Rep. 2016;6:37114.

11. Li F, Fan XX, Chu C, Zhang Y, Kou JP, Yu BY. A strategy for optimizing the combination of active components based on Chinese medicinal formula ShengMai-San for myocardial ischemia. Cell Physiol Biochem. 2018;45:1455-71.

12. Newgard CB. Metabolomics and metabolic diseases: where do we stand? Cell Metab. 2017;25:43-56.

13. Fan Y, Li Y, Chen Y, Zhao YJ, Liu LW, Li J, et al. Comprehensive metabolomic characterization of coronary artery diseases. J Am Coll Cardiol. 2016;68:1281-93.

14. Zhang L, Wei TT, Li Y, Li J, Fan Y, Huang FQ, et al. Functional metabolomics characterizes a key role for $\mathrm{N}$-acetylneuraminic acid in coronary artery diseases. Circulation. 2018;137:1374-90.

15. Li Z, Hou J, Deng Y, Zhi H, Wu W, Yan B, et al. Exploring the protective effects of Danqi Tongmai tablet on acute myocardial ischemia rats by comprehensive metabolomics profiling. Phytomedicine. 2019;1:152918.

16. Gao E, Lei YH, Shang X, Huang ZM, Zuo L, Boucher M, et al. A novel and efficient model of coronary artery ligation and myocardial infarction in the mouse. Circ Res. 2010;107:1445-53.

17. Guo H, Zhang Z, Su Z, Sun C, Zhang X, Zhao X, et al. Enhanced anti-tumor activity and reduced toxicity by combination andrographolide and bleomycin in ascitic tumor-bearing mice. Eur J Pharmacol. 2016;776:52-63.

18. He B, Zhao Y, Xu L, Gao L, Su Y, Lin N, et al. The nuclear melatonin receptor ROR a is a novel endogenous defender against myocardial ischemia/reperfusion injury. J Pineal Res. 2016;60:313-26.

19. Gromski PS, Muhamadali $\mathrm{H}$, Ellis DI, Xu Y, Correa E, Turner ML, et al. A tutorial review: metabolomics and partial least squares-discriminant analysis-a marriage of convenience or a shotgun wedding. Anal Chim Acta. 2015;879:10-23.

20. Boccard J, Rutledge DN. A consensus orthogonal partial least squares discriminant analysis (OPLS-DA) strategy for multiblock Omics data fusion. Anal Chim Acta. 2013;769:30-9.

21. Pennell D. MR as a diagnostic tool in heart disease: what is the future? MAGMA. 1998;6:189-90.

22. Shahid A, Patel VB, Morton JS, Stenson TH, Davidge ST, Oudit GY, et al. Low altitude simulation without hypoxia improves left ventricular function after myocardial infarction by reducing ventricular afterload. PLoS ONE. 2019;14:e0215814.

23. Zhao ZQ, Morris CD, Budde JM, Wang NP, Muraki S, Sun HY, et al. Inhibition of myocardial apoptosis reduces infarct size and improves regional contractile dysfunction during reperfusion. Cardiovasc Res. 2003;59:132-42.

24. Rabbani N, Thornalley PJ. Hidden complexities in the measurement of fructosyllysine and advanced glycation end products for risk prediction of vascular complications of diabetes. Diabetes. 2015;64:9-11.
25. Chen CJ, Liao WL, Chang CT, Lin YN, Tsai FJ. Identification of urinary metabolite biomarkers of type 2 diabetes nephropathy using an untargeted metabolomic approach. J Proteome Res. 2018;17:3997-4007.

26. Sibilitz KL, Benn M, Nordestgaard BG. Creatinine, eGFR and association with myocardial infarction, ischemic heart disease and early death in the general population. Atherosclerosis. 2014;237:67-75.

27. Deidda M, Piras C, Cadeddu Dessalvi C, Congia D, Locci E, Ascedu F, et al. Blood metabolomic fingerprint is distinct in healthy coronary and in stenosing or microvascular ischemic heart disease. J Transl Med. 2017;15:112-30.

28. Salabei JK, Lorkiewicz PK, Holden CR, Li Q, Hong KU, Bolli R, et al. Glutamine regulates cardiac progenitor cell metabolism and proliferation. Stem Cells. 2015;33:2613-27.

29. Czibik G, Steeples V, Yavari A, Ashrafian H. Citric acid cycle intermediates in cardioprotection. Circ Cardiovasc Genet. 2014;7:711-9.

30. Pedersen ER, Tuseth N, Eussen SJ, Ueland PM, Strand E, Svingen GF, et al. Associations of plasma kynurenines with risk of acute myocardial infarction in patients with stable angina pectoris. Arterioscler Thromb Vasc Biol. 2015;35:455-62.

31. Shad KF, Luqman N, Simpson AM. Peripheral biomarker for vascular disorders. Biomark Insights. 2018;13:1177271918812467.

32. Clarke NR, Kelion AD, Nixon J, Hilton-Jones D, Forfar JC. Does cytosine-thymineguanine (CTG) expansion size predict cardiac events and electrocardiographic progression in myotonic dystrophy? Heart. 2001;86:411-6.

33. Lee JK, Zaidi SH, Liu P, Dawood F, Cheah AY, Wen WH, et al. A serine elastase inhibitor reduces inflammation and fibrosis and preserves cardiac function after experimentally-induced murine myocarditis. Nat Med. 1998;4:1383-91.

34. Choudhary C, Weinert BT, Nishida Y, Verdin E, Mann M. The growing landscape of lysine acetylation links metabolism and cell signalling. Nat Rev Mol Cell Biol. 2014;15:536-50.

35. Schreckenberg R, Weber P, Cabrera-Fuentes HA, Steinert I, Preissner KT, Bencsik $P$, et al. Mechanism and consequences of the shift in cardiac arginine metabolism following ischaemia and reperfusion in rats. Thromb Haemost. 2015;113:482-93.

36. Page JH, Ma J, Chiuve SE, Stampfer MJ, Selhub J, Manson JE, et al. Plasma total cysteine and total homocysteine and risk of myocardial infarction in women: a prospective study. Am Heart J. 2010;159:599-604.

37. Dhar I, Lysne V, Seifert R, Svingen GFT, Ueland PM, Nygård OK, et al. Plasma methionine and risk of acute myocardial infarction: Effect modification by established risk factors. Atherosclerosis. 2018;272:175-81.

38. Tommy WS, Israel G, Galia B. Cysteine proteases in atherosclerosis. FEBS J. 2017;284:1455-72.

39. Eltzschig HK, Robson SC. NT5E mutations and arterial calcifications. N Engl J Med. 2011;364:432-42.

40. Kolwicz SC Jr, Purohit S, Tian R. Cardiac metabolism and its interactions with contraction, growth, and survival of cardiomyocytes. Circ Res. 2013;113:603-16.

41. Headrick JP, Peart JN, Reichelt ME, Haseler LJ. Adenosine and its receptors in the heart: regulation, retaliation and adaptation. Biochim Biophys Acta. 2011;1808:1413-28.

42. Obata T, Nakashima M. Oxidative stress inactivates ecto-5'-nucleotidase by inhibiting protein kinase $C$ in rat hearts in vivo. Eur J Pharmacol. 2017;805:125-30.

43. ten Hove M, Lygate CA, Fischer A, Schneider JE, Sang AE, Hulbert K, et al. Reduced inotropic reserve and increased susceptibility to cardiac ischemia/reperfusion injury in phosphocreatine-deficient guanidinoacetate-N-methyltransferaseknockout mice. Circulation. 2005:111:2477-85.

44. Hemalatha T, Balachandran C, Manohar BM, Nayeem M, Subramaniam S, Sharma $\mathrm{HS}$, et al. Myocardial expression of PDECGF is associated with extracellular matrix remodeling in experimental myocardial infarction in rats. Biochem Cell Biol. 2010;88:491-503.

45. Zhao JY, Qiao B, Duan WY, Gong XH, Peng QQ, Jiang SS, et al. Genetic variants reducing MTR gene expression increase the risk of congenital heart disease in Han Chinese populations. Eur Heart J. 2013:35:733-42.

46. Wen J, Grenz A, Zhang Y, Dai Y, Kellems RE, Blackburn MR, et al. A2B adenosine receptor contributes to penile erection via PI3K/AKT signaling cascade-mediated eNOS activation. FASEB J. 2011;25:2823-30. 